IZA DP No. 8137

Tax Incidence in the Presence of Tax Evasion

Philipp Doerrenberg

Denvil Duncan

April 2014

Forschungsinstitut

zur Zukunft der Arbeit

Institute for the Study

of Labor 


\title{
Tax Incidence in the Presence of Tax Evasion
}

\author{
Philipp Doerrenberg \\ ZEW Mannheim, \\ CGS at University of Cologne and IZA
}

Denvil Duncan

Indiana University

and IZA

\section{Discussion Paper No. 8137 \\ April 2014}

\author{
IZA \\ P.O. Box 7240 \\ 53072 Bonn \\ Germany \\ Phone: +49-228-3894-0 \\ Fax: +49-228-3894-180 \\ E-mail: iza@iza.org
}

Any opinions expressed here are those of the author(s) and not those of IZA. Research published in this series may include views on policy, but the institute itself takes no institutional policy positions. The IZA research network is committed to the IZA Guiding Principles of Research Integrity.

The Institute for the Study of Labor (IZA) in Bonn is a local and virtual international research center and a place of communication between science, politics and business. IZA is an independent nonprofit organization supported by Deutsche Post Foundation. The center is associated with the University of Bonn and offers a stimulating research environment through its international network, workshops and conferences, data service, project support, research visits and doctoral program. IZA engages in (i) original and internationally competitive research in all fields of labor economics, (ii) development of policy concepts, and (iii) dissemination of research results and concepts to the interested public.

IZA Discussion Papers often represent preliminary work and are circulated to encourage discussion. Citation of such a paper should account for its provisional character. A revised version may be available directly from the author. 


\section{ABSTRACT}

\section{Tax Incidence in the Presence of Tax Evasion*}

This paper studies the effect of tax evasion on the economic incidence of sales taxes. We design a laboratory experiment in which buyers and sellers trade a fictitious good in double auction markets. A per-unit tax is imposed on sellers, and sellers in the treatment group are provided the opportunity to evade the tax whereas sellers in the control group are not. We find that the market equilibrium price in the treatment group is economically and statistically lower than in the control group. This result is consistent with a theoretical model in which access to evasion opportunities reduces the effective tax rate and therefore dampens real behavioral responses. Our findings suggest that the benefits of tax evasion are not limited to the side of the market with access to evasion but are partly shifted to the non-evading side of the market. We discuss the implications of our findings for the distributional and welfare effects of taxes.

JEL Classification: H21, H22, H26, H3, D44

Keywords: tax evasion, tax incidence, double auction

Corresponding author:

Denvil Duncan

School of Public and Environmental Affairs

Indiana University

1315 East 10th Street

Bloomington, IN 47403

USA

E-mail: duncande@indiana.edu

\footnotetext{
* We would like to thank Ernesto Reuben for sharing the z-tree code on his website. Bradley Heim, Max Loeffler, Nathan Murray, Andreas Peichl, Arno Riedl, Justin Ross, Sebastian Siegloch and participants at the National Tax Association conference 2013 provided helpful comments and suggestions.
} 


\section{Introduction}

The standard textbook theory of taxation makes the prediction that the economic incidence of a tax solely depends on the relative elasticity of demand and supply. The tax burden will fall disproportionately on consumers if demand is more inelastic than supply and more on producers if supply is more inelastic than demand. However, there is evidence that the incidence of a tax also depends on other factors such as tax salience (Chetty et al. 2009) and remittance policy (Slemrod 2008). ${ }^{1}$

Another factor likely to drive the incidence of taxes is the prevalence of tax evasion opportunities. Intuitively, access to tax evasion allows taxpayers to lower their effective tax rate by reducing their tax base. As a result, the "real" behavioral responses that determine tax incidence are likely to differ between taxpayers who can evade and those who cannot. $^{2}$ Understanding this possible source of deviation between observed and standard theoretical economic incidence is important given the prevalence of tax evasion in both developed and developing countries (Slemrod 2007; Schneider et al. 2010; Kleven et al. 2011). Although the impact of tax evasion on incidence has intuitive appeal and is policy relevant, theoretical evidence is mixed (Marrelli 1984; Yaniv 1995; Bayer and Cowell 2009), and there is very little empirical evidence.

The objective of this paper, therefore, is to contribute empirical evidence on the effect of tax evasion on tax incidence. The specific research question is, do sellers with tax evasion opportunities trade their goods and services at different prices than they otherwise would if no tax evasion opportunities existed? In other words, are equilibrium prices different in markets where evasion is an option relative to markets without evasion opportunities? We design an economic laboratory experiment with between-subject variation in which subjects trade fictitious goods in a double auction. Subjects are randomly assigned roles as sellers or buyers in treatment and control groups. A per-unit tax is imposed on all sellers. In the treatment group, sellers are able to under-report the number of units sold, whereas in the control group the tax liability is paid automatically (as with exact withholding). The only difference between the treatment and control group is that sellers in the treatment group can evade the sales tax. Therefore, we identify the impact of evasion on tax incidence by comparing the equilibrium prices in the treatment group with that in the control group.

The experimental laboratory has been used extensively to study the economic incidence of taxes. In fact, various studies have found that the theoretical results of tax incidence - without evasion - hold in competitive experimental markets such as a double auction (Kachelmeier et al. 1994; Borck et al. 2002; Ruffle 2005). We therefore intro-

\footnotetext{
${ }^{1}$ The literature is reviewed in detail further below.

${ }^{2}$ By real response we are referring to behavioral changes that directly affect decisions such as leisure, consumption or production (Slemrod 1995).
} 
duce tax evasion to an environment that has been shown to provide credible results in the context of tax incidence. ${ }^{3}$ Relying on the controlled environment of the laboratory also means that we are able to avoid much of the econometric problems of observational data analyses and thus produce clean identification of the treatment effect. Achieving causal identification using observational data requires random variation in access to evasion across otherwise similar markets. This is obviously difficult to achieve since access to tax evasion is most likely one of the dimensions of a market that determines whether buyers and sellers select to participate in that market.

We place our empirical question in a theoretical framework based on the standard textbook partial equilibrium approach to tax incidence. The model shows that access to tax evasion changes the incidence of the tax. More specifically, an increase in the statutory tax rate leads to a smaller increase in the market price if sellers are non-compliant relative to a market with full compliance; this impact on incidence is increasing in the noncompliance rate. The simple reason for this result is that sellers with an evasion option are able to reduce their effective tax rate relative to those without evasion. As a result, the tax causes the supply curve to shift up by less in the case with evasion. In our specific context, a per-unit tax on sellers who can evade taxes reduces the share of the statutory tax burden that is passed on to buyers.

Our empirical results confirm the theoretical prediction. In particular, the equilibrium price in the treatment group with tax evasion is statistically and economically lower than in the control group. Accordingly, the number of units traded is higher in the case with evasion. By under-reporting sales, sellers reduce their effective tax burden, which allows them to sell at lower prices. Although the statutory burden on buyers is lower in the presence of tax evasion, we find evidence that sellers shift the full expected effective tax rate onto buyers. As expected, the smaller impact on the market equilibrium results in a much lower partial equilibrium excess burden in the presence of tax evasion. ${ }^{4}$

Addressing the research question posed in this paper makes several important contributions to the literatures on tax incidence, tax salience and tax evasion. First, several studies have attempted to identify the incidence of taxes using observational data. For example, Alm et al. (2009) and Marion and Muehlegger (2011) find that the incidence of the fuel tax in the US is fully shifted to final consumers and related to supply and demand conditions, Saez et al. (2012) find that tax equivalence does not hold in the context of the Greek payroll tax, and Fuest et al. (2013) find that the burden of local

\footnotetext{
${ }^{3}$ We employ an experimental double auction similar to Grosser and Reuben (2013). Riedl (2010) provides an overview of experimental tax incidence research.

${ }^{4}$ Tax evasion opportunities also have a negative effect on generated tax revenue; revenue is higher in the control than in the treatment group. However, the foregone tax revenue represents a transfer to private agents and does not affect welfare as long as one does not impose a welfare function that gives higher weight to tax financed public goods relative to private consumption.
} 
business taxes in Germany partly falls on employees via lower wages. ${ }^{5}$ To overcome the challenges of identifying causal effects using observational data, several studies explore the question of economic incidence in a laboratory setting. For example, Kachelmeier et al. (1994), Quirmbach et al. (1996), Borck et al. (2002), and Ruffle (2005) find that the theoretical predictions of tax incidence hold true in a competitive laboratory market with full information. ${ }^{6}$ We add to this strand of the literature by introducing tax evasion to a standard competitive experimental double-auction market and show that this changes the incidence of the tax. This finding is important because it suggests that tax equivalence, which is the focus of the existing laboratory tax incidence literature, is unlikely to hold in the real world where buyers and sellers have different access to evasion (Slemrod 2008).

Two studies more closely related to ours in that they estimate economic incidence in the presence of tax evasion are Alm and Sennoga (2010) and Kopczuk et al. (2013). The latter provides empirical evidence that the stage of production at which the tax on diesel is collected in the US affects the economic incidence of the tax. Although they suggest that this difference is driven by variation in access to evasion across production stages, reliance on observational data makes it difficult to cleanly identify whether this effect is fully due to variation in compliance behavior. Alm and Sennoga (2010) use a computable general equilibrium (CGE) model to simulate the economic incidence of tax evasion for a "typical" developing country. They find that the benefits of evasion generally do not stay with the evader if there is free entry, which suggests that evasion changes the incidence of taxes. Since we rely on the controlled environment of the lab, our empirical approach provides precise control over the market institutions, which allows us to randomize access to evasion and measure non-compliance accurately. As a result, we are able to offer cleaner identification of the impact of tax evasion on the economic incidence of the tax than these two studies. Nonetheless, we view our work as complementary to these papers. The illusive nature of tax evasion implies that consistent results across multiple techniques is required if we are to draw firm conclusions about causes and consequences of tax evasion. We argue that our results, combined with Kopczuk et al. (2013) and Alm and Sennoga (2010), provide evidence that the standard textbook model of tax incidence does not hold up in many real world applications.

Second, our paper is related to the tax salience literature, which shows that the standard theoretical incidence result may not hold if taxes are not salient. For example, Chetty et al. (2009) show in the field that people under-react to taxes that are added at the register relative to taxes that are shown in the displayed price of goods. Simi-

\footnotetext{
${ }^{5}$ Other examples of observational tax incidence studies include Evans et al. (1999), Gruber and Koszegi (2004), and Rothstein (2010).

${ }^{6}$ Kerschbamer and Kirchsteiger (2000) and Riedl and Tyran (2005) find that the laws of tax incidence do not translate to non-competitive experimental market.
} 
larly, Sausgruber and Tyran (2005) find in a lab experimental context that indirect taxes exhibit a different incidence than direct taxes because indirect taxes are less visible. ${ }^{7}$ Similar to the salience effects described in Chetty et al. (2009), we provide evidence that the willingness and opportunity to evade taxes dampens "real" behavioral responses to taxation. Taxpayers who evade taxes do not adjust their economic behavior in response to changes in the tax rate by as much as if evasion was not an option. The dampening effect on "real" behavioral responses changes the incidence of the tax just as if the tax was not salient to the taxpayer.

Finally, our paper adds to the general tax evasion literature. Naturally, obtaining credible causal evidence in the context of tax evasion is very difficult using observational studies (Slemrod and Weber 2012). A broad strand of literature has therefore employed lab experiments to study evasion (e.g., Fortin et al. 2007; Alm et al. 2009; Balafoutas et al. 2014). ${ }^{8}$ However, unlike most of the tax evasion literature, we focus on the implications of tax evasion (e.g., Doerrenberg and Duncan 2014) rather than on explaining tax evasion (e.g., Alm 2012). In particular, like Doerrenberg and Duncan (2014), we show that real responses to taxes are small in part because of income shifting responses such as tax evasion.

Our findings also have important policy implications related to the distribution of tax burden and the effectiveness of tax policy as a tool for influencing behavior. First, understanding the impact of tax evasion on the economic incidence of taxes is important for the correct evaluation of the distributional effect of tax policies aimed at reducing tax evasion. The results we present here further suggest that accounting for tax evasion in incidence studies may lead to a re-evaluation of the progressivity/regressivity of various taxes. For example, a sales tax where the benefits of evasion stay with sellers is likely to be more regressive than one where the benefits are shifted to buyers, especially if the evading sellers sell mostly to lower income individuals. This finding is important for empirical analysis of the distributional implications of tax reform proposals.

Second, taxes aimed at influencing real behavior are likely to be less effective if the market participants responsible for remitting the tax have access to tax evasion opportunities. Because the effective tax rate is lower among evaders, "real" behavioral responses to the tax are dampened, which limits the ability of the tax to achieve desired behavioral outcomes. For example, a number of states in the U.S. are now considering the adoption of road mileage user-fees as a replacement for fuel taxes (Duncan and Graham 2013). The salience of road mileage user-fees suggests that they are likely to reduce vehicle miles traveled. According to our results, this desirable outcome is unlikely to

\footnotetext{
${ }^{7}$ Further examples of salience effects in the field are Finkelstein (2009) and Gallagher and Muehlegger (2011). Abeler and Jaeger (2013) and Blumkin et al. (2012) study questions related to salience effects in a laboratory setting.

${ }^{8}$ Andreoni et al. (1998) and Torgler (2002) provide surveys on tax compliance in experiments.
} 
occur if mileage user-fees are administered in ways that facilitate tax evasion via odometer tampering, say. More generally, to the extent that tax evasion cannot be fully eliminated, our findings suggest that it might be optimal to apply higher tax rates to goods sold in markets with evasion opportunities (e.g., Cremer and Gahvari 1993). Not only could this be more efficient, but it might also achieve the desired adjustments in behavior.

The relevance and importance of these policy implications is especially obvious when one considers the prevalence of tax evasion across the world (Slemrod 2007; Schneider et al. 2010; Kleven et al. 2011). Transaction taxes, which we focus on in our study, are of particular interest in this context. For example, sales tax gap estimates range from 2 percent to 41 percent for the value added tax in the European Union and 1 percent to 19.5 percent for the retail sales tax in the United States (see Mikesell 2014 for a review of sales tax evasion estimates). Additionally, it is generally accepted that 'use' tax evasion by both businesses and individuals is much higher than retail sales tax evasion; e.g., GAO (2000) assume non-compliance rates of 20 to 50 percent among businesses and 95 to 100 percent among individuals in a study of the potential revenue losses of e-commerce. ${ }^{9}$

Therefore, our results are relevant in countries such as the United States where, for example, a number of states have adopted, or are in the process of adopting, legislation aimed at (a) restricting the sale of "zappers", which are used to evade sales taxes, and (b) requiring online traders to register as sales tax collectors. Our findings suggest that such measures are likely to result in higher prices as affected sellers fully adjust to the retail sales tax. While we focus on sales taxes here, the findings also suggest that other anti-tax evasion initiatives, such as the Foreign Account Tax Compliance Act (FATCA), are likely to affect the level of economic activity as affected parties respond to the reduced evasion opportunities.

The remainder of the paper is as follows. We describe the experimental design in section 2 , the theoretical framework in section 3 and the results in section 4 . Our findings are discussed in section 5 and section 6 concludes.

\section{Experimental Design}

\subsection{Overview}

The experimental design reflects a standard competitive experimental double auction market as pioneered by Smith (1962). ${ }^{10}$ The auction and the parameters in our exper-

\footnotetext{
${ }^{9}$ Consumers in the United States are required to pay 'use' tax in lieu of the retail sales tax if the seller is not required - by law - to register as a tax collector in the consumers' state.

${ }^{10}$ Double auction markets mimic a perfectly competitive market. Dufwenberg et al. (2005), for example, rely on an experimental double auction to study financial markets. Holt (1995) provides an overview.
} 
iment are based on Grosser and Reuben (2013). In each round of the double auction market, 5 buyers and 5 sellers trade two units of a homogeneous and fictious good. Sellers are assigned costs for each unit and buyers are assigned values. The roles of sellers and buyers as well as the costs and values are exogenous and randomly assigned to the lab participants. We impose a per-unit tax on sellers to this set-up and give sellers in the treatment group the opportunity to evade the tax whereas sellers in the control group pay the per-unit tax automatically (as with exact withholding). We employ a betweensubjects design where each participant is either in the control or treatment group. Further details on the experimental design are provided in the next subsections.

\subsection{Organization}

The experiment was conducted in the Cologne Laboratory for Economic Research (CLER), University of Cologne, Germany. A large random sample of all subjects in the laboratory's subject pool of approximately 4000 persons was invited via email - using the recruitment software ORSEE (Greiner 2004) - to participate in the experiment. Participants signed up on a first-come-first-serve basis. Neither the content of the experiment nor the expected payoff was stated in the invitation email. The experiment was programmed utilizing $z$-tree software (Fischbacher 2007). We ran eight sessions over two regular school days in November and December 2013. ${ }^{11}$ Each session consisted of either a control or treatment group market and lasted about 100 minutes (including review of instructions and payment of participants).

We conduct four control and four treatment sessions for a total of 80 subjects. $^{12}$ Experimental Currency Units (ECU) are used as the currency during the experiment. After the experiment, ECU are converted to Euro with an exchange of 30 ECU $=1$ EUR and subjects are paid the sum of all net incomes (see below) in Euro. It was public information that all tax revenue generated in the experiment would be donated to the German Red Cross.

At the beginning of each session, subjects are randomly assigned to computer boothes by drawing an ID number out of a bingo bag upon entering the lab. The computer then randomly assigns each subject to role as buyer or seller, as well as her costs or values which stay constant during the experiment. Subjects are given a hard copy of the instructions when they enter the lab and are allowed as much time as needed to familiarize themselves with the procedure of the experiment. They are also allowed to

\footnotetext{
${ }^{11}$ There are two regular semesters at the tertiary level in Germany; winter semester lasting from October to March and summer semester between April and July. Therefore, the experiment was implemented during the regular semester.

${ }^{12}$ While this appears to be low, note that Grosser and Reuben (2013), for example, only implemented four markets and yet have sufficient statistical power to identify a treatment effect. See section 4.2.1 for summary statistics on demographic characteristics of the participants.
} 
ask any clarifying questions.

\subsection{Description of a session}

Each session includes 1 market that is either a control or treatment group market. Each market has five buyers and five sellers who each have 2 units of a fictitious good to trade. Sellers and buyers are randomly assigned costs and values for both of their units; the roles as buyer or seller and the assigned values and costs are exogenously determined and stay constant for the entire experiment. All ten subjects in one session/market first trade in 3 practice rounds and then 27 payoff relevant rounds.

Trade in the Double Auction As is common in experimental markets, subjects are given demand and supply schedules for a fictitious good at the beginning of the session (Ruffle 2005; Cox et al. 2012; Grosser and Reuben 2013). The demand schedule for buyers assigns a value to each of two items and the supply schedule for sellers assigns a cost to each of two items. The cost/value of the units vary across items and subjects as illustrated in Table 1. This allows us to induce demand and supply curves for each market, which are depicted in Figure 1. The schedules are chosen such that demand and supply elasticities are equal in equilibrium. The demand and supply schedules remain fixed across periods in a given session, and they do not differ between control and treatment markets.

Subjects trade the good in a double auction market that is opened for two minutes in each period. During this time, each seller can post an "ask" that is lower than the current ask on the market, but higher than the cost of the item to the seller. In other words, sellers cannot trade an item below its cost. Additionally, sellers must sell their cheaper unit before they sell their more expensive unit. Similarly, each buyer can post a "bid" that is higher than the current bid on the market, but lower than the value of the item to the buyer. Therefore, buyers cannot buy an item at a price that exceeds its value. Buyers must also buy their most valued item before their least valued item. The lowest standing ask and the highest standing bid are displayed on the computer screen of all ten market participants. ${ }^{13}$

An item is traded if a seller accepts the standing buyer bid or a buyer accepts the standing seller ask. Subjects are not required to trade a minimum amount of items, items that are not traded yield neither costs nor profits. Traders are not allowed to communicate with each other. This trading procedure is identical for the treatment and control groups.

\footnotetext{
${ }^{13}$ Figure 8 in the appendix depicts a screenshot of the experimental market place for a seller in the treatment group with evasion opportunity.
} 
Income: Control Group Gross-income in each period consists of the sum of the profit on each unit traded. Sellers' gross profit on each unit is equal to the difference between the selling price and cost, while buyers' profit on each unit is the difference between value and price paid. All subjects (buyers and sellers) are told that sellers have to pay a per-unit tax for each unit sold, that the tax rate is fixed across all periods at $\tau=10$ ECU per-unit and that the tax is collected at the end of every third trading period. In other words, subjects complete three rounds of trading then tax is collected from sellers, then three more rounds of trading then another tax collection and so on. This yields 27 trading periods and 9 tax collections; we discuss this design feature below. We define total gross profit in each trading period $i(i=1,2,3, \ldots, 25,26,27)$ as

$$
\Pi_{i}^{s}=P_{i 1} d_{1}+P_{i 2} d_{2}-C_{1} d_{1}-C_{2} d_{2}
$$

for sellers and

$$
\Pi_{i}^{b}=V_{1} d_{1}+V_{2} d_{2}-P_{i 1} d_{1}-P_{i 2} d_{2}
$$

for buyers. Superscripts $s$ and $b$ indicate seller and buyer, respectively, $d_{j}=1$ if good $j$ is traded and 0 otherwise, $P_{i j}$ is the price of good $j$ in period $i, C_{j}$ is the cost of good $j$ and $V_{j}$ is the value of good $j$.

Because taxes are collected at the end of every third trading period, a seller's net income for each tax collection period $k(k=3,6,9,12,15,18,21,24,27)$ is equal to:

$$
\pi_{k}^{s}=\Pi_{k}^{s}+\Pi_{k-1}^{s}+\Pi_{k-2}^{s}-\tau U
$$

where $U$ is the total number of units sold in the last three rounds and $\tau=10$ is the statutory per-unit tax rate. Because buyers do not pay a tax, their net income for each tax collection period may be written as:

$$
\pi_{k}^{b}=\Pi_{k}^{b}+\Pi_{k-1}^{b}+\Pi_{k-2}^{b}
$$

Both buyers and sellers are shown their gross income after every trading period and their net income after every tax collection period. Subjects' final payoff is the sum of their net incomes from the nine tax collection periods.

Income: Treatment Group Since buyers do not pay the tax, the calculation of gross and net income for buyers in the treatment group is identical to that of the control group: see equations (2) and (4). Sellers, on the other hand, make a tax reporting decision at the end of every third round. In other words, subjects complete three rounds of trading then sellers make a reporting decision; then three more rounds of trading then another reporting decision and so on. 
One advantage of allowing subjects to report after every third trading period is that it increases the probability that every subject has a positive amount to report and must therefore explicitly decide if they wish to under-report sales for tax purposes. Another advantage of using every third round is that it yields 9 reporting decisions. This is advantageous because it means that subjects can learn the implications of tax evasion for their profits and update their beliefs about the probability of being caught. As a result, we can be assured that the market equilibrium in the evasion treatment reflects the impact of tax evasion on the behaviour of market participants. Although reporting every period would maximize the number reporting decisions, we opted against this option because excess supply in the market implies that some subjects will sell zero units in a given trading period, which trivializes the reporting decision. Another option is to have subjects make a single reporting decision at the end of the experiment. While this approach maximizes the chance that everyone has a positive amount to report, having a single reporting decision would not allow subjects to learn or update their beliefs. We opted for every third round as a reasonable compromise between these two extremes. ${ }^{14}$

Sellers can report any number between 0 and the true amount sold in the previous three trading periods, and the reported amount is taxed at $\tau=10$ ECU per-unit. Sellers face an exogenous audit probability of $\gamma=0.1$ (10 percent) and pay a fine, which is equal to twice the evaded taxes if they underreport sales and are audited. The tax rate, audit probability, and fine rate are fixed across periods and sessions, and all subjects buyers and sellers - in the treatment group receive this information at the beginning of the experiment.

Therefore, unlike sellers in the control group who must pay taxes on each unit sold, sellers in the treatment group are able to evade the sales tax by underreporting sales. Sellers' gross income in any trading period $i$ is the same as in equation (1), but their net income in each tax collection period is rewritten as:

$$
\pi_{k}^{s}= \begin{cases}\prod_{k}^{s}+\Pi_{k-1}^{s}+\Pi_{k-2}^{s}-\tau R & \text { if not audited } \\ \prod_{k}^{s}+\Pi_{k-1}^{s}+\Pi_{k-2}^{s}-\tau U-\tau(U-R) & \text { if audited }\end{cases}
$$

where $R$ is the reported number of units sold, $U$ is the number of units actually sold over the last three rounds, and $\tau=10$ is the statutory per-unit tax rate. Subjects' final payoff is the sum of their net incomes from the nine tax collection periods.

\footnotetext{
${ }^{14}$ Although subjects in the control group do not make a reporting decision, we collect taxes and report their net profits at the end of every third period to ensure comparability with the treatment group.
} 


\subsection{Market Equilibrium}

The demand and supply schedules described in Table 1 and displayed in Figure 1 can be used to determine the competitive equilibrium price and quantity with and without the per-unit tax. Theoretically, we expect the market to clear with 7 units traded at any price in the range $48 \mathrm{ECU}$ to $52 \mathrm{ECU}$ in the case without taxes. We obtain a range of prices in equilibrium because the demand schedule is stepwise linear (Ruffle 2005; Cox et al. 2012; Grosser and Reuben 2013). ${ }^{15}$

A per-unit tax on sellers increases the cost of each unit by 10 ECU and thus shifts the supply curve to the left as shown in Figure 1. In the absence of tax evasion opportunities, this theoretically produces a new equilibrium quantity of 6 units, which is supported by an equilibrium price in the range of $53 \mathrm{ECU}$ to 57 ECU. Because the demand and supply schedules have equal elasticity in equilibrium, the incidence of the tax should theoretically be shared equally between buyers and sellers; buyers pay an extra 5 ECU and sellers receive 5 ECU less (after paying the tax).

The question we seek to answer is whether this equilibrium outcome is affected by the presence of tax evasion opportunities among sellers. The next section provides a theoretical discussion for why tax evasion may or may not affect the incidence of the tax.

\section{Theoretical Context}

This section places our experimental design in the context of a simple theoretical set-up based on the textbook partial equilibrium analysis of tax incidence. It is straight forward to show that the standard text book results hold for the control group because they have no evasion opportunity. In particular, the incidence of the tax is determined solely by the relative elasticity of demand and supply. We want to know if and how these predictions change when the person legally responsible for remitting the tax has access to evasion opportunities. Therefore, the analysis that follows focuses on the treatment group where the opportunity to evade the tax exists. However, as shown below, the model describing the control group is nested within the model described here.

\subsection{Buyers' and Sellers' Decision}

Consider a market where buyers and sellers trade $q$ units of a good at price $p$ in a given trading period. Sellers have to pay a per-unit (excise) tax for each unit they sell, but are provided a tax reporting decision. As a result, the per-unit tax $\tau$ is paid on $r(0 \leq r \leq q)$,

\footnotetext{
${ }^{15}$ Grosser and Reuben (2013) conducted an experiment using the same demand and supply schedule as we do and find that the "no-tax" equilibrium is equal to that predicted by the theory. Therefore, although we do not implement the "no-tax" treatment here, we expect that our "no-tax" equilibrium is in line with theoretical expectations.
} 
which is the number of units reported by a seller. The tax reporting decision is audited with probability $\gamma$, and because all audits lead to the full discovery of actual sales, a fine equal to twice the evaded taxes, $2(q-r) \tau$, must be paid if audited.

Buyers Buyers are never allowed an evasion opportunity so their only choice variable is the number of traded units; they simply maximize

$$
\pi^{B}=(v-p) q
$$

with respect to $q$, where $v$ is the assigned value the buyer receives from each unit bought. This is maximized where the price paid for the last unit is equal to the value of that unit to the buyer $v=p$. Aggregated, this suggests that market demand is a function of price, $D(p)$.

Sellers On the other hand, sellers maximize expected profits $\pi^{S}$, which are given by:

$$
\pi^{S}=(p-c) q-r \tau-2 \gamma(q-r) \tau
$$

where $c$ is the assigned cost of each unit sold by a seller. Equation (7) can be rewritten as:

$$
\pi^{S}=(p-c) q-q \underbrace{\tau(\phi+2(1-\phi) \gamma)}_{\text {effective tax } t_{e}},
$$

where $\phi=r / q(0 \leq \phi \leq 1)$ is the share of actual sales that is reported for tax purposes. Sellers face an expected effective tax rate $t_{e}=\tau(\phi+2(1-\phi) \gamma)$ for each unit they actually sell. ${ }^{16}$ It is clear that the effective tax rate differs from the statutory tax rate as long as $\phi \neq 1$. In fact, the effective tax rate is lower than the statutory rate as long as sales are underreported $(\phi<1)$ and the chance of being audited is less than one half $\gamma<1 / 2$. Additionally, the effective tax rate is positively related to the statutory tax rate $\tau\left(\frac{\delta t_{e}}{\delta \tau} \geq 0\right)$, the share of reported income $\phi\left(\frac{\delta t_{e}}{\delta \phi}>0\right.$ for $\left.\gamma<0.5\right)$ and the audit probability $\gamma\left(\frac{\delta t_{e}}{\delta \gamma} \geq 0\right)$. Note that because sellers in the control group do not have an opportunity to evade the tax, their reported sales is equal to their actual sales; i.e., $r=q$, which implies that $\phi=1$. As a result, the effective tax rate $t_{e}$ is equal to the statutory tax rate $\tau$ in the control group.

Sellers chose the number of traded units $q$ and the share of reported sales $\phi$ to maximize their expected profits $\pi^{S}$. Maximizing equation (8) yields the following first order conditions (F.O.C.) with respect to $q$ and $\phi$ :

\footnotetext{
${ }^{16}$ For reasons of brevity, we henceforth refer to $t_{e}$ as the effective tax rate, rather than expected effective tax rate.
} 


$$
\begin{aligned}
& p=c+t_{e} \\
& \gamma=1 / 2
\end{aligned}
$$

These F.O.C. define the optimum and have the usual interpretations: sellers trade until the revenue from the last unit sold is equal to its cost, and some amount of sales is underreported if the chance of being caught is no more than one half.

Note that the effective tax rate $t_{e}$ equals the statutory tax rate $\tau$ when the audit probability is $\gamma=1 / 2$. This implies that the optimal output $q^{*}$ is defined by $p=c+\tau$, which is identical to the $q^{*}$ in the control group. ${ }^{17}$ The optimal output in the treatment group is also identical to that in the control group if sellers report honestly, which is predicted to occur if $\gamma>1 / 2$. Intuitively, the effective tax rate is greater than the statutory tax rate if the audit probability is greater than one half, except when $\phi=1$. Therefore, sellers can maximize their expected profit by reporting honestly when the chance of being audited is greater than one half. By reporting honestly in this case, sellers ensure that $t_{e}=\tau$, which yields the same $q^{*}$ as in the control group. Therefore, the opportunity to evade the tax has no effect on sellers output decisions if the audit probability is equal or larger than $50 \%$. This further implies that the opportunity to evade has no effect on the incidence of the tax.

However, the optimal strategy for any audit probability $\gamma$ smaller than $1 / 2$ is to fully evade. Since $\gamma$ is 0.1 in our experiment, the model predicts that sellers do not report any of their sold units. With this optimal strategy of full evasion $(\phi=0)$, the effective tax rate reduces to $t_{e}=2 \gamma \tau$, which is less than the statutory tax $\tau$ since $\gamma=0.1$. In this case, the F.O.C. with respect to $q$ reduces to $p=c+2 \gamma \tau$. Because unit costs and the statutory tax rate are equal in both treatment and control groups, it follows that the price in the treatment group (evasion possible) is lower than in the control group (evasion not possible).

This optimal solution assumes that sellers are fully rational and therefore evade all units due to the low audit probability. However, the existing tax evasion literature shows that most empirically observed evasion rates are lower than suggested by standard theory (Alm 2012). Our experimental results also support this observation; despite the low audit probability of 0.1 we observe an average compliance rate of $7 \%$. That is, $\phi$ is larger than zero in our experiment. However, only 33 out of 40 sellers report non-zero sales in any given reporting period, which suggests that most sellers behave rationally as predicted by the theory and that $\phi<1$. Therefore, the non-zero compliance rate reflects

\footnotetext{
${ }^{17}$ To see this, recall that $\phi=1$ in the control group because there is no opportunity to evade the tax. Substituting this value into equation (8) and optimizing over $q$ yields $p=c+\tau$.
} 
the effect of a combination of full and partial evaders. ${ }^{18}$

So how does the incidence of the tax in the treatment group compare to that in the control group? We address this question in the next section for a general case where market compliance is greater than zero and smaller than one, i.e. $0 \leq \phi \leq 1$.

\subsection{Market outcome}

Consider the empirical case where $0 \leq \phi \leq 1$. The F.O.C. with respect to $q$ implies that market supply is implicitly defined not only by the price $p$ but also by the effective tax rate $t_{e}$, which in turn depends on $\tau, \phi$ and $\gamma$. This allows us to express market supply as a function of $p$ and $t_{e}: S\left(p, t_{e}\right)$. We already showed that market demand is defined by $D(p)$ because each buyer's $q^{*}$ depends on the price only. As has been shown in the literature, an experimental double auction market clears the market so that demand equals supply:

$$
D(p)=S\left(p, t_{e}\right)
$$

The equilibrium condition is differentiated implicitly with respect to $p$ and $\tau$ to determine the incidence of the statutory excise tax $\tau$ :

$$
\frac{d p}{d \tau}=\frac{\partial t_{e}}{\partial \tau} \frac{\partial S}{\partial t_{e}} \frac{1}{\frac{\partial D}{\partial p}-\frac{\partial S}{\partial p}}
$$

The incidence result is equivalent to the textbook case except for parameter $\frac{\partial t_{e}}{\partial \tau}=\phi(1-$ $2 \gamma)+2 \gamma \cdot \frac{\partial t_{e}}{\partial \tau}$ equals 1 as long as the effective tax rate is equal to the statutory tax rate. This is the case in the control group where there is no evasion opportunity. ${ }^{19}$ Therefore, the incidence of the tax in the treatment group is lower than in the control group if $\frac{\partial t_{e}}{\partial \tau}$ is smaller than 1. It is easy to show that, conditional on $\gamma<1 / 2$, this is the case as long as $\phi<1$. In other words, we expect the market equilibrium price in the presence of tax evasion to be lower than in the case where tax evasion is not possible as long as some units are evaded $(\phi<1)$. This follows from the fact that the statutory tax rate is only due on reported units and therefore has less of an impact if a positive amount of units is evaded, i.e., the effective tax rate will be lower than the statutory rate as long as we do not see full compliance.

To see this more clearly, rewrite equation (11) in terms of elasticities:

$$
\frac{d p}{d \tau}=\frac{\partial t_{e}}{\partial \tau} \frac{\epsilon_{S, \tau}}{\epsilon_{S, p}-\epsilon_{D, p}}
$$

\footnotetext{
${ }^{18}$ One could define the difference between the "irrational" $\phi>0$ and the rational $\phi=0$ as a parameter for an exogenously given level of irrationality.

${ }^{19}$ Note that this is also the case if everyone in the treatment group reports honestly. However, we do not consider this case here since our empirical observation shows less than full compliance.
} 
where $\epsilon_{S, \tau}$ is the supply elasticity with respect to the tax rate $\tau$, and $\epsilon_{S, p}$ and $\epsilon_{D, p}$ are the supply and demand elasticities with respect to the price. In our experimental design, supply elasticities equal demand elasticities in equilibrium. Assuming that $\epsilon_{S, \tau}=\epsilon_{S, p}$, the incidence result can hence be rewritten: ${ }^{20}$

$$
\frac{d p}{d \tau}=\frac{\partial t_{e}}{\partial \tau} \frac{1}{2}
$$

In the control group where evasion is not possible $\frac{\partial t_{e}}{\partial \tau}=1$ and a 1 unit increase in the tax rate increases the price by $1 / 2$ units. On the other hand, a 1 unit increase in the tax rate in the treatment group - where evasion is possible - increases the price by $(\phi(1-2 \gamma)+2 \gamma) \times 1 / 2$ units, which is less than $1 / 2$ as long as $\phi<1$ (recall that $\gamma<0.5$ in our experiment).

The intuition for this result is fairly straight forward. Since $\phi<1$ implies that the effective tax rate is lower than the statutory tax rate, sellers who evade are less responsive to changes in the statutory tax rate than sellers who report honestly. Therefore, as long as some firms evade the tax, the industry supply curve shifts up by a smaller margin than would be observed in the absence of tax evasion. This is illustrated in Figure 2 . First, consider panel A in Figure 2, which represents the control group where evasion is not possible. The supply curve generally shifts up by the effective tax rate. Because the effective tax rate equals the statutory tax rate in the case without evasion, the supply curve shifts up by the full amount of the statutory rate. This results in a new market equilibrium $\left(p_{c}^{*}, q_{c}^{*}\right)$; subscript $\mathrm{c}$ indicates control group.

On the other hand, the supply curve in the treatment group - shown in panel B of Figure 2 - shifts up by the effective tax rate, which is less than the statutory rate as long as $\phi<1$. This results in a new market equilibrium $\left(p_{t}^{*}, q_{t}^{*}\right)$ where $\left(p_{t}^{*}<p_{c}^{*}\right)$ and $\left(q_{t}^{*}>q_{c}^{*}\right)$; subscript t indicates treatment group. Also note that the difference between the two equilibria increases with evasion and is maximized if all sellers in the treatment group fully evade the tax. This difference in price suggests that some of the benefits of evasion are shifted to buyers in the form of lower prices.

\section{Empirical Strategy and Results}

Recall that we are interested in identifying the impact of tax evasion opportunities on the economic incidence of a sales tax. We describe the empirical strategy used to identify this treatment effect in section 4.1 and our findings in section 4.2.

\footnotetext{
${ }^{20}$ This is a fair assumption because the tax is highly salient in our experiment.
} 


\subsection{Empirical Strategy}

Given the discussion in section 3, we are particularly interested in knowing whether the market clearing price in the treatment group is different from the price in the control group. Therefore, the first step in our empirical strategy is to define the market price. The experiment produced one price for each unit sold in a given market-period, which allows us to create three measures of market price. The first measure is simply the price at which each item is sold, which we denote $P$. We also calculate the mean and median price in a given market-period and denoted them $\bar{P}$ and $P_{50}$, respectively. Therefore, our data set has one observation per market-period when price is measured by $\bar{P}$ or $P_{50}$ and $n$ observations per market-period when market price is measured by $P$, where $n$ is the number of units sold in that market-period. ${ }^{21}$

Second, due to random assignment to groups and markets, any (non-parametric) difference in these prices between the treatment and control groups is taken as evidence of the presence of treatment effects. We also test for treatment effects parametrically by regressing each measure of price, separately, on a treatment dummy. The baseline model for $\bar{P}$ is specified as follows:

$$
\bar{P}_{i, m}=\beta_{0}+\delta T_{m}+\epsilon_{i, m},
$$

where $\bar{P}_{i, m}$ is the mean price of the good in period $i$ (with $i=1, \ldots, 27$ ) of market $m$ (with $m=1, \ldots, 8) . T_{m}$ is a dummy for the treatment state, which is equal to one if treatment group and zero if control group. $\epsilon_{i, m}$ is a standard error term. Our coefficient of interest is $\delta$, which represents the difference in market price between the two groups. More precisely, $\delta$ indicates the causal effect of evasion opportunity on the equilibrium market price. This causal interpretation follows from the fact that the groups are identical except for access to evasion and random assignment of participants to the two groups.

We set up our data as a panel with 27 periods per market and run pooled ordinary least squares (OLS) regressions with standard errors clustered on market. OLS regressions yield unbiased results because random selection into treatments cause the error term to be uncorrelated with our explanatory variable of interest in each period. ${ }^{22}$ Because the treatment status of each market and hence the participants in that market is always the same, the treatment effect (parametric and nonparametric) is identified using a betweenmarket design. ${ }^{23}$ We include period fixed effects in some specifications.

\footnotetext{
${ }^{21}$ The minimum number of units sold in a market period is 5 and maximum is 7 . Therefore, $n$ ranges from 5 to 7 .

${ }^{22}$ Note that estimators that allow for censoring, such as Tobit models, are unnecessary since the market price is not censored. Although the market price could be no lower than 18 and no higher the 82, the distribution of market prices suggest that these prices were never binding; the lowest market price is 30 and the highest is 63 .

${ }^{23}$ Notice that this also implies that it is not possible to estimate the treatment effect in the presence
} 


\subsection{Results}

\subsubsection{Demographics of Participants}

After the experiment, subjects reported their age, gender, native language, level of tax morale and field of study. Tax morale is determined using a question very similar to one used in the World Values Survey (Inglehart nd). ${ }^{24}$ Each of these variables is summarized in Table 2. Casual observation of the data shows that randomization into the treatment states worked well. This is confirmed by non-parametric Wilcoxon rank-sum tests for differences in distributions between groups (Wilcoxon 1945; Mann and Whitney 1947); we do not observe any statistically significant differences in gender, age, share of participants whose native language is German, tax morale or field of study across the two groups. While we do not explicitly measure other attitudinal variables such as social norms or preferences, randomization implies that these omitted variables are also balanced across groups and therefore do not have any effect on our results.

Among all participants, approximately $51 \%$ were male, $77 \%$ indicated German to be their native language, and the average age was 26 years. Approximately $24 \%$ of subjects stated that cheating on taxes can never be justified and $48 \%$ indicated that economics is their major field of study.

\subsubsection{Compliance and effective tax rate}

Our hypothesis that markets with evasion opportunities clear at lower prices requires that sellers actually underreport sales. The empirical results show that this condition is satisfied. We find that every subject evaded some positive amount of sales at least once and 33 of the 40 subjects in the treatment group fully pursued the profit maximizing rational strategy of full evasion in every reporting period. As a result the mean compliance rate is approximately $7 \%$ among all sellers in treatment group and $61 \%$ among those who report non-zero sales. ${ }^{25}$

Recall that the effective tax rate $t_{e}$ can be written as $\tau(\phi+2(1-\phi) \gamma)$. Substituting

of market fixed effects. Each individual is randomly assigned to a market and everyone in the market has the same treatment status. Therefore, the treatment status of a market is the same as the treatment status of the individuals trading in that market.

24 "Please tell me for the following statement whether you think it can always be justified, never be justified, or something in between: 'Cheating on taxes if you have the chance'." This is the most frequently used question to measure tax morale in observational studies (e.g., Alm and Torgler 2006, Halla 2012 and Doerrenberg and Peichl 2013).

${ }^{25}$ This level of evasion is at the high end of evasion estimates in the experimental tax evasion literature (e.g., Fortin et al. 2007; Alm et al. 2009; Alm et al. 2010; Coricelli et al. 2010). However, these studies focus on income taxes and are therefore not directly comparable to our results. We do not know of any sales tax experiments in the tax evasion literature. Evidence from the real world suggest that our compliance rates are not unreasonable. For example, the compliance rate in our experiment is comparable to the compliance rate for the 'use' tax in the United States; 0 to 5 percent among individuals (GAO 2000). 
the exogenously determined statutory tax rate $(\tau=10 \mathrm{ECU})$ and audit probability $(\gamma=$ 0.1 ), and rearranging the expression, yields $t_{e}=2+8 \phi$. Therefore, the average effective tax rate depends on the average compliance rate and, in our case, is approximately $t_{e}=2.56 \mathrm{ECU}(=2+8 \times 0.07){ }^{26}$

We combine this effective tax rate with the demand and supply schedules shown in Table 1 and Figure 1 in order to predict the equilibrium price and quantity in the treatment group. As shown in Figure 1, a per unit tax shifts the supply curve up. However, unlike the control group, the supply curve only shifts up by 2.56 ECU in the treatment group, thus producing a new equilibrium with price in the range of 50.65 to 52 ECU and 7 units. Consistent with the theoretical model, this price is lower than the predicted equilibrium price range for the control group: 53 to 57 ECU (see section 2.4).

\subsubsection{Price}

Non-parametric results The non-parametric results presented in Figures 3 and 4 and Table 3 show clearly that the price in the treatment group is lower than in the control group. Figure 3 reports the mean market price by period for the treatment and control groups. The data show that the mean market price varied a lot in both groups in the first 10 to 14 trading periods. This is consistent with the existing literature, which generally finds that double auction markets take approximately 8 to 10 rounds to converge (Ruffle 2005).

Although price in both groups converged in roughly same number of periods, the evolution of prices is different. Price increased steadily to equilibrium in the treatment group, and behave erratically in the control group. For this reason, and as is common in the literature, our primary results are based on data from trading periods 14 to 27; we provide results for the full sample for illustrative purposes. The mean market price in both groups stabilized after round 14: at approximately $\mathbf{5 4 . 3 5}$ ECU in the control group and 51.63 ECU in the treatment group (see panel B of Table 3). These observed market prices are well within the equilibrium price ranges predicted by the theoretical model; see sections 2.4 and 4.2.2. This confirms that the experimental results are consistent with the theoretical predictions, which increases our confidence in the results.

More importantly, the mean market price in the treatment group is $2.72 \mathrm{ECU}$ lower than in the control group. This represents the estimated treatment effect and it is statistically different from zero at the $1 \%$ level according to the Wilcoxon rank-sum test. In other words, we find that markets with access to tax evasion trade at lower prices than markets without access to tax evasion. ${ }^{27}$ Figure 4 and the second column of Table

\footnotetext{
${ }^{26}$ The average effective tax rate is obviously lower among those who fully evade $\left(t_{e}=2\right.$ ECU) and higher among those who partially evade $\left(t_{e}=6.88 \mathrm{ECU}\right)$. In either case, the effective tax rate is sufficiently different from the statutory tax rate to generate a treatment effect as predicted by the theoretical model.

${ }^{27}$ Note that the estimated treatment effect is larger for the full sample (panel A). Because this sample
} 
3 show that the treatment effect is qualitatively the same when we use median market price instead of mean market price; in this case the treatment effect is ECU 3.00. ${ }^{28}$

Parametric results We extend the analysis above by estimating equation (14) for the mean market price as the dependent variable. The estimated treatment effect reported in Panel B of Table 4 ranges from -2.65 ECU to -2.70 ECU and is statistically different from zero at the 1 percent level. ${ }^{29}$ Additionally, the estimates are robust to the inclusion of period fixed effects (model 2), demographic covariates (model 3) and both period fixed effects and demographic covariates (model 4). They are also robust to the definition of price as demonstrated by the results in Table 5. Estimating equation (14) with the median market price $P_{50}$ as our dependent variable yields treatment effects of -1.60 ECU to -2.10 ECU that are statistically different from zero at the $1 \%$ level (see Panel A of Table 5). Although these estimates are approximately 0.70 to 1.00 ECU smaller than that reported in Panel B of Table 4, they remain economically meaningful. ${ }^{30}$ These results confirm our earlier non-parametric findings that the market price in the treatment group is lower than in the control group.

\subsubsection{Units sold}

Non-parametric results The theoretical predictions in section 3 suggests that treatment markets will clear at a lower price and higher quantity than the control group. We have already demonstrated that the market clearing price is lower in the treatment group. This section shows that the treatment group also sold more units than the control group. The results in Table 3 show that the mean number of units sold per period in the control group is 5.96, which is close to the 6 units predicted by the theoretical model. On the other hand, the treatment group sold an average of 6.5 units per period. Although this is slightly below that predicted by the theoretical model, it is statistically different from the number of units sold in the control group at the $1 \%$ level. In other words, the estimated treatment effect of 0.5 units is statistically different from zero. The difference in sales

includes data before the market price converges, we prefer the estimate in panel B.

${ }^{28}$ Further evidence that tax evasion affects the incidence of a tax is provided in Figures 6 and 7 , which report the cumulative distribution of mean and median market prices, respectively, for the treatment and control groups. Both figures show clearly that the price in the control group is not drawn from the same distribution as that in the treatment group. This conclusion is supported by the Kolmogorov-Smirnov test for equality of distribution functions; in both cases we reject the null that the distributions are equal. This result also holds when we use the individual ask prices $(P)$ instead of mean or median prices; results available upon request.

${ }^{29}$ Panel A of Table 4 reports the results for the full sample. These results are reported for illustrative purposes only since the market does not clear until around period 14 .

${ }^{30} \mathrm{We}$ also estimate the model with the ask price for each unit sold as the dependent variable and report the results in Panel $\mathrm{B}$ of Table 5. The estimated treatment effect in this case is -2.66 ECU to -2.72 ECU, which is almost identical to that for the mean market price as reported in Panel B of Table 4. 
between the two groups is more obvious when we look at the total number of units sold by each group. Again, restricting attention to trading periods 15 to 27 (after the market clears), we find that the treatment group sold a total of 336 units while the control group only sold 308 units. Corresponding numbers for periods 1 to 27 are 704 and 647 in the treatment and control group, respectively.

Parametric results These results are supported by results from a regression analysis that are reported in Table 6. Focussing on Panel B, which reports results for periods 15 to 27 , we find a treatment effect of 0.6 units; relative to the control group, the treatment group sold approximately 0.6 more units per period.

\section{Discussion}

The results presented in section 4.2 show that markets with sellers who have the opportunity to evade taxes trade more units and do so at lower prices than markets where tax evasion is not possible. Section 5.1 explains the incidence results in the context of the theoretical model and section 5.2 describes the welfare implications. The external validity of our findings is discussed in section 5.3.

\section{$5.1 \quad$ Incidence}

The treatment effect identified above is very much consistent with the theoretical model in section 3. According to the theoretical framework, tax evasion lowers the effective tax rate facing sellers, thus allowing them to trade at lower prices in a competitive market. As a result, the final tax burden shifted to buyers is lower than it would otherwise be in the absence of tax evasion. This is exactly what we find; the mean compliance rate ranges from $0 \%$ among full evaders to $61 \%$ among partial evaders with an average of $7 \%$ among all sellers. This implies an average effective tax rate of 2 ECU among full evaders and 6.88 ECU among partial evaders for an average of approximately 2.56 ECU among all sellers. Because the market is competitive, sellers facing these lower effective tax rates trade at lower prices in an effort to maximize their profits.

So how does this response among sellers affect the incidence of the tax? In order to answer this question, we fist have to determine the incidence of the tax in the control group, which requires knowing the market equilibrium in the absence of the tax. Although we did not run a "no-tax" treatment, we are able to estimate this "no-tax" equilibrium by relying on evidence from Grosser and Reuben (2013) who run a "no-tax" treatment using a comparable double auction market with the same demand and supply schedule 
as we do. ${ }^{31}$ In line with the theoretical expectation, they find a mean market price of $49 \mathrm{ECU}$ and 7 units in the "no-tax" equilibrium. On the other hand, the market in our control group (with tax but no evasion opportunity) cleared with a mean price of 54.35 ECU and 5.96 units, which is well within the equilibrium predicted by the theory: 53 ECU to 57 ECU with 6 units traded.

More importantly, this equilibrium price is approximately 5 ECU above the "notax" equilibrium of 49 ECU. This suggests that the incidence of the tax burden in the control group is shared equally between buyers and sellers since the tax rate is 10 ECU per unit. Again, this is consistent with the theoretical framework; since the demand and supply schedules have equal elasticity in equilibrium, the burden is expected to be shared equally between buyers and sellers.

The next step is to determine the extent to which access to evasion affected the incidence of the tax. The mean market clearing price in the treatment group (with tax and evasion opportunity) is $51.63 \mathrm{ECU}$, which is within the 50.65 to $52 \mathrm{ECU}$ price range we predicted given the empirical compliance rate $(7 \%)$ and mean effective tax rate 2.56 ECU (see section 4.2.2). Considering the statutory tax rate of 10 ECU per unit, this implies that buyers in the treatment group pay $26.4 \%(51.64-49) / 10$ of the statutory tax burden, compared to the $50 \%$ in the case without evasion. In other words, access to evasion reduced the statutory tax burden on buyers by about 23 percentage points.

This result would seem to suggest that sellers bear the greater share of the tax burden despite equal supply and demand elasticities. To see that this is incorrect, consider the following exercise. For simplicity, consider the mean effective tax rate of 2.56 ECU. If sellers with evasion opportunity continued to share the effective tax burden 50-50, we would expect the price in the treatment group to increase by approximately $1.28 \mathrm{ECU}$ $(=2.56 / 2)$ relative to the "no-tax" equilibrium; that is to 50.28 . However, this is not what we observe. The price in the treatment group is 51.63 ECU, which suggest that sellers shift the full effective tax rate onto buyers; buyers bear 2.63 ECU $(=51.63-49)$ even though the effective tax rate is 2.56 ECU. As a result, about $102.7 \%(=(51.63-49) / 2.56)$ of a seller's effective tax rate is shifted onto buyers.

\subsection{Welfare Implications}

Because we find that markets with access to evasion trade a lower prices and higher quantity, we expect the efficiency cost of the tax to be lower in market where tax evasion

\footnotetext{
${ }^{31}$ The experimental design in Grosser and Reuben (2013) differs from ours in that they use a within subject design where each subject trades in a market with and without the tax. We are aware that within subject and between subject designs may yield different results (Charness et al. 2012). However, we argue that their "no-tax" estimate is a reasonable baseline to use in our incidence analysis, especially since they randomized the order of tax and "no-tax" treatments. Additionally, their result is in line with the theoretical prediction which is further support for using their result as a baseline result.
} 
is possible. Our induced demand and supply curves along with our estimated equilibrium price and quantity allows us to do a back-of-the-envelope calculation to approximate the impact of evasion on the deadweight loss of the per unit tax. For simplicity, we assume linear demand and supply schedules in the following calculations and estimate the partial equilibrium deadweight loss as the area of the Harberger triangle. ${ }^{32}$ The estimated equilibria for the average trading period are (49 ECU, 7 units), (54.35 ECU, 5.96 units) and (51.65 ECU, 6.5 units) for "no-tax", control, and treatment, respectively. This implies that the deadweight loss of the 10 ECU per unit tax in the control group where there is no access to evasion is approximately $5.50 \mathrm{ECU}(=1 / 2 * 10 *(7-5.9))$ per trading period. This scales up to approximately 71.5 ECU across all market clearing trading periods in the control group.

For the treatment group we consider the case where the effective tax rate is 2.56 ECU, which is over-shifted to buyers; recall that buyers pay 2.63 ECU more than in the "no-tax" baseline. Using the mechanics of the simple partial equilibrium model, the supply curve has to shift up by 5.26 ECU for the buyers' price to increase by 2.63 ECU and quantity to fall to 6.5 units. Using these numbers, we get a deadweight loss of 1.32 ECU $(=1 / 2 * 5.26 *(7-6.5))$ per trading period. This scales up to approximately 17.1 ECU across all market clearing trading periods in the treatment group. Therefore, the deadweight loss of the tax is much lower in the treatment group than in the control group. Table 7 summarizes our results.

There are three important things to note about the calculations shown above. First, the calculations assume that tax evasion is costless except for the fine. In particular, tax evasion does not require any real resource costs in our experiment. Therefore, the excess burden is limited to the changes in the market outcome: quantity sold and price. To the extent that tax evasion requires real resource costs, the reduction in excess burden caused by evasion is likely to be partially offset by the cost of real resources used to facilitate evasion. ${ }^{33}$ Second, we exclude the impact on tax revenue since the foregone tax revenue represents a transfer to private agents and does not affect welfare as long as one does not impose a welfare function that gives higher weight to tax financed public goods relative to private consumption.

Third, our calculations hold the tax rate constant rather than tax revenue. It can be shown that the difference in excess burden between the treatment and control group would be smaller if a revenue requirement is imposed. This follows from the fact that a lower tax rate would be required in the control group in order to generate the same

\footnotetext{
${ }^{32}$ Note that these are uncompensated estimates of deadweight loss, which overestimates the traditionally favored compensated estimates. For this reason, we focus on the difference in deadweight loss between the two groups rather than the level of the deadweight loss.

${ }^{33}$ The absence of real resource costs in our experiment is comparable to 'use' tax evasion by individuals who purchase goods online. Purchasing goods online in order to evade the sales tax, arguably, involves smaller resource costs than visiting a store front in person.
} 
amount of revenues as the treatment group. Since the excess burden is increasing in the square of the tax rate, a lower tax rate would imply a substantially smaller excess burden in the control group than the amount shown above. In fact, it is possible for markets without tax evasion opportunities to generate smaller excess burdens than markets with evasion opportunities, if the compliance rate is very low.

\subsection{External Validity}

As with all economic laboratory experiments, there remains doubt about the external validity of our results. ${ }^{34}$ One major concern is that the setting in the lab is abstract and artificial. However, the literature shows that laboratory double auctions generate very plausible equilibria (e.g., Smith 1962; Holt 1995; Dufwenberg et al. 2005; Grosser and Reuben 2013.). Although subjects trade in fictitious goods, they receive actual money pay-offs and thus face incentives similar to buyers and sellers in actual markets. Furthermore, the question of tax incidence has been widely studied in the laboratory setting (e.g., Riedl and Tyran 2005; Ruffle 2005; Cox et al. 2012; Grosser and Reuben 2013) and shown to lead to results that reflect theoretical predictions very well.

In order to make the tax evasion decision as realistic as possible we used actual tax terminology and announced to the participants that all tax revenue would be donated to the German Red Cross, a non-ideological charity organization that is usually perceived as reliable and transparent. ${ }^{35}$ Although evasion may occur among buyers as well, the realworld problem seems to be more relevant among sellers; sellers are usually responsible for remitting sales taxes to the government. In this sense, our laboratory setting mimics the operation of most transaction taxes in the real world and thus reflects the more relevant "real-world" sales tax evasion concerns.

It is also often argued that the stakes in lab experiments are too small to interpret the outcomes as realistic. This is unlikely to be true in our case because our average pay-off of EUR 19.63 is relatively high and, to give an idea of its purchasing power in Cologne, roughly corresponds to eight full lunch meals in the student cafeteria at Cologne University. ${ }^{36}$ Furthermore, many experiments conducted in locations where the stakes were equivalent to more than a month's earnings find very similar results to conventional "small-stake" experiments (Slonim and Roth 1998). Additionally, it is question-

\footnotetext{
${ }^{34}$ See Levitt and List (2007) for a critical discussion of the generalizability of lab experiments. Falk and Heckman (2009) offer a defense of most concerns, some of which are also discussed here.

${ }^{35}$ Tax morale research (Torgler 2007) finds that taxpayers are more likely to comply with tax laws if they believe that the tax revenue is spent transparently. Eckel and Grossman (1996) show that dictators share more in dictator games if the recipient is the American Red Cross. Overall, we donated EUR 288 to the Red Cross.

${ }^{36}$ The show-up fee is equivalent to one meal. The cafeteria at University of Cologne is the most popular spot for students to buy their daily lunch.
} 
able whether high stakes render a more realistic setting, since most "real-life" decisions do not involve massive amounts of money either (Falk and Heckman 2009). Another concern is the reliance on university students as participants. Many experiments with non-student populations find results comparable to experiments with students (Charness and Kuhn 2011; Falk et al. 2013). Furthermore, Alm et al. (2011) compare students to non-students in tax compliance experiments and find that the reporting responses of students to policy innovations are largely the same as those of non-students in identical experiments and "real" people in non-experiment environments.

\section{Conclusion}

We use data generated in an economic laboratory experiment to identify the effect of tax evasion among sellers on the economic incidence of a per-unit tax. We find strong evidence that access to evasion opportunities affect the incidence of a per-unit tax. In particular, sellers who are able to evade a per-unit tax trade at lower prices and sell more units. In fact, relative to the baseline case where buyers face $50 \%$ of the statutory tax burden, buyers in the treatment group only face approximately $26.4 \%$ of the statutory tax burden. Although buyers pay lower prices than they otherwise would, we find that sellers fully shift the expected effective tax onto buyers. Partial equilibrium welfare analysis reveal that evasion options reduce the excess burden of taxation and increase welfare. However, the latter result may change if a revenue requirement is imposed.

Our findings suggest that access to evasion reduces the effectiveness of taxes that are implemented with the specific intent of changing the activity level of market participants. Furthermore, because evasion reduces the amount of the tax that is shifted onto buyers, our findings also suggest that sales taxes may be more or less regressive than we think depending on which part of the income distribution benefits most from the evading activities of sellers.

The results also imply that policy makers do not necessarily have an easy choice when deciding whether to pursue evasion reducing strategies or to exploit the potential efficiency gains of evasion. For example, Cremer and Gahvari (1993) show that the optimal Ramsey rule in the presence of tax evasion calls for higher tax rates on the good with the tax evasion opportunity. The argument is that evasion lowers the real behavioral response and thus lowers excess burden; this is confirmed by our results. However, given that governments often face revenue requirements along with the fact that tax evasion may require real resource costs, we prefer a strategy that seeks to minimize tax evasion opportunities. This is especially important in cases where the policy objective is to influence real behavior. Evasion reducing strategies may also make sense on revenue grounds. Although revenues represent a simple transfer from an economic welfare perspective, rev- 
enues are used to produce public goods/service that are likely to be underproduced or not produced at all as tax revenues decline.

Finally, while we show that tax evasion opportunities affect tax incidence, it is not clear that the magnitude and effect is the same across all types of taxes. Conditional on the ease with which taxes can be evaded, it is also possible that the mechanism of evasion matters. For example, Tran and Nguyen (2014) show that Vietnamese firms evade VAT by artificially increasing their sales and material costs, which is facilitated by colluding with other producers in the supply chain. The presence of collusion as a means of evasion suggests lower competitive pressure, which may lead to different incidence outcomes under a VAT compared to retail sales taxes where collusion among firms is not necessary for evasion. Given recent calls for the adoption of VAT in the USA, we argue that this potential difference is worth investigating in future research. More generally, it would be interesting to know if and how evasion mechanisms in different tax systems affect the incidence of taxes.

\section{References}

Abeler, J. and S. Jaeger (2013). Complex tax incentives - an experimental investigation. CESifo Working Paper Series No 4231.

Alm, J. (2012). Measuring, explaining, and controlling tax evasion: lessons from theory, experiments, and field studies. International Tax and Public Finance 19(1), 54-77.

Alm, J., K. M. Bloomquist, and M. McKee (2011). Comparing student and non-student reporting behavior in tax compliance experiments. In A. Plumley (Ed.), IRS Research Bulletin (Publication 1500), pp. 93-99. Washington D.C.: International Revenue Service.

Alm, J., T. Cherry, M. Jones, and M. McKee (2010). Taxpayer information assistance services and tax compliance behavior. Journal of Economic Psychology 31(4), 577586.

Alm, J., B. R. Jackson, and M. McKee (2009). Getting the word out: Enforcement information dissemination and compliance behavior. Journal of Public Economics 93(3-4), 392-402.

Alm, J., E. Sennoga, and M. Skidmore (2009). Perfect competition, urbanization, and tax incidence in the retail gasoline market. Economic Inquiry 47(1), 118-134.

Alm, J. and E. B. Sennoga (2010). Mobility, competition, and the distributional effects of tax evasion. National Tax Journal 63(4), 1055-84.

Alm, J. and B. Torgler (2006). Culture differences and tax morale in the United States and in Europe. Journal of Economic Psychology 27(2), 224 - 246. 
Andreoni, J., B. Erard, and J. Feinstein (1998). Tax compliance. Journal of Economic Literature 36(2), 818-860.

Balafoutas, L., A. Beck, R. Kerschbamer, and M. Sutter (2014). The hidden costs of tax evasion: collaborative tax evasion in markets for expert services. University of Innsbruck Working Papers in Economics and Statistics 2014-01.

Bayer, R. and F. Cowell (2009). Tax compliance and firms' strategic interdependence. Journal of Public Economics 93(11-12), 1131-1143.

Blumkin, T., B. J. Ruffle, and Y. Ganun (2012). Are income and consumption taxes ever really equivalent? evidence from a real-effort experiment with real goods. European Economic Review 56(6), 1200-1219.

Borck, R., D. Engelmann, W. Müller, and H.-T. Normann (2002). Tax liabilityside equivalence in experimental posted-offer markets. Southern Economic Journal 68(3), 672-682.

Charness, G., U. Gneezy, and M. A. Kuhn (2012). Experimental methods: Betweensubject and within-subject design. Journal of Economic Behavior \& Organization 81(1), $1-8$.

Charness, G. and P. Kuhn (2011). Lab labor: What can labor economists learn from the lab? In O. Ashenfelter and D. Card (Eds.), Handbook of Labor Economics Vol 4A, pp. 229-330. Amsterdam: North Holland.

Chetty, R., A. Looney, and K. Kroft (2009). Salience and taxation: Theory and evidence. American Economic Review 99(4), 1145 - 77.

Coricelli, G., M. Joffily, C. Montmarquette, and M. Villeval (2010). Cheating, emotions, and rationality: an experiment on tax evasion. Experimental Economics 13(2), 226247.

Cox, J. C., M. Rider, and A. Sen (2012). Tax incidence: Do institutions matter? an experimental study. Experimental Economics Center Working Paper Series No 2012-17.

Cremer, H. and F. Gahvari (1993). Tax evasion and optimal commodity taxation. Journal of Public Economics 50(2), 261 - 275.

Doerrenberg, P. and D. Duncan (2014). Experimental evidence on the relationship between tax evasion opportunities and labor supply. European Economic Review. forthcoming.

Doerrenberg, P. and A. Peichl (2013). Progressive taxation and tax morale. Public Choice 155(3-4), $293-316$.

Dufwenberg, M., T. Lindqvist, and E. Moore (2005). Bubbles and experience: An experiment. American Economic Review 95(5), 1731-1737. 
Duncan, D. and J. Graham (2013). Road user fees instead of fuel taxes: The quest for political acceptability. Public Administration Review 73(3), 415-426.

Eckel, C. C. and P. J. Grossman (1996). Altruism in anonymous dictator games. Games and Economic Behavior 16(2), 181-191.

Evans, W., J. Ringel, and D. Stech (1999). Tobacco taxes and public policy to discourage smoking. In J. Poterba (Ed.), Tax Policy and the Economy, Volume 13. Cambridge, USA: MIT Press.

Falk, A. and J. J. Heckman (2009). Lab experiments are a major source of knowledge in the social sciences. Science 326(5952), 535-538.

Falk, A., S. Meier, and C. Zehnder (2013). Do lab experiments misrepresent social preferences? The case of self-selected student samples. Journal of the European Economic Association 11(4), 839-852.

Finkelstein, A. (2009). E-Z tax: Tax salience and tax rates. The Quarterly Journal of Economics 124(3), 969 - 1010.

Fischbacher, U. (2007). z-tree: Zurich toolbox for ready-made economic experiments. Experimental Economics 10(2), 171-178.

Fortin, B., G. Lacroix, and M.-C. Villeval (2007). Tax evasion and social interactions. Journal of Public Economics 91(11-12), 2089-2112.

Fuest, C., A. Peichl, and S. Siegloch (2013). Do higher corporate taxes reduce wages? micro evidence from germany. IZA Discussion Papers 7390, Institute for the Study of Labor (IZA).

Gallagher, K. S. and E. Muehlegger (2011). Giving green to get green? incentives and consumer adoption of hybrid vehicle technology. Journal of Environmental Economics and Management 61(1), $1-15$.

GAO (2000). Sales taxes: Electronic commerce growth presents challenges; revenue losses are uncertain. US Government Accounting Office (GAO): Report to Congressional Requesters No. GAO/GGD/OCE-00-165, Washington D.C.

Greiner, B. (2004). An online recruitment system for economic experiments. In K. Kremer and V. Macho (Eds.), Forschung und wissenschaftliches Rechnen 2003. GWDG Bericht 63, pp. 79-93. Goettingen: Ges. fuer Wiss. Datenverarbeitung.

Grosser, J. and E. Reuben (2013). Redistribution and market efficiency: An experimental study. Journal of Public Economics 101 (May), 39 - 52.

Gruber, J. and B. Koszegi (2004). Tax incidence when individuals are time-inconsistent: the case of cigarette excise taxes. Journal of Public Economics 88(9-10), 1959-1987. 
Halla, M. (2012). Tax morale and compliance behavior: First evidence on a causal link. The B.E. Journal of Economic Analysis 8 Policy 12(1).

Holt, C. A. (1995). Industrial organization: A survey of laboratory research. In J. H. Kagel and A. E. Roth (Eds.), The handbook of experimental economics, pp. 349 443. Priceton, USA: Prince- ton University Press.

Inglehart, R. (n.d.). Values change the world. http://worldvaluessurvey.org/ (accessed April 2010).

Kachelmeier, S. J., S. T. Limberg, and M. S. Schadewald (1994). Experimental evidence of market reactions to new consumption taxes. Contemporary Accounting Research 10(2), 505-545.

Kerschbamer, R. and G. Kirchsteiger (2000). Theoretically robust but empirically invalid? an experimental investigation into tax equivalence. Economic Theory 16(3), 719-734.

Kleven, H. J., M. B. Knudsen, C. T. Kreiner, S. Pedersen, and E. Saez (2011). Unwilling or unable to cheat? evidence from a tax audit experiment in denmark. Econometrica 79(3), $651-692$.

Kopczuk, W., J. Marion, E. Muehlegger, and J. Slemrod (2013). Do the laws of tax incidence hold? point of collection and the pass-through of state diesel taxes. Mimeo.

Levitt, S. D. and J. A. List (2007). What do laboratory experiments measuring social preferences reveal about the real world? The Journal of Economic Perspectives $21(2), 153-174$.

Mann, H. B. and D. R. Whitney (1947). On a test whether one of two random variables is stochastically larger than the other. Annals of Mathematical Statistics 18, 50-60.

Marion, J. and E. Muehlegger (2011). Fuel tax incidence and supply conditions. Journal of Public Economics 95(9-10), 1202 - 1212.

Marrelli, M. (1984). On indirect tax evasion. Journal of Public Economics 25(1-2), $181-196$.

Mikesell, J. (2014). Misconceptions about value-added and retail sales taxes: are they barriers to sensible tax policy? Public Budgeting 8 Finance, Forthcoming.

Quirmbach, H. C., C. W. Swenson, and C. C. Vines (1996). An experimental examination of general equilibrium tax incidence. Journal of Public Economics 61(3), $337-358$.

Riedl, A. (2010). Behavioral and experimental economics do inform public policy. FinanzArchiv: Public Finance Analysis 66(1), 65-95. 
Riedl, A. and J.-R. Tyran (2005). Tax liability side equivalence in gift-exchange labor markets. Journal of Public Economics 89(11-12), 2369-2382.

Rothstein, J. (2010). Is the EITC as good as an NIT? Conditional cash transfers and tax incidence. American Economic Journal: Economic Policy 2(1), 177-208.

Ruffle, B. J. (2005). Tax and subsidy incidence equivalence theories: experimental evidence from competitive markets. Journal of Public Economics 89 (8), 1519-1542.

Saez, E., M. Matsaganis, and P. Tsakloglou (2012). Earnings determination and taxes: Evidence from a cohort-based payroll tax reform in greece. The Quarterly Journal of Economics 127(1), 493-533.

Sausgruber, R. and J.-R. Tyran (2005). Testing the mill hypothesis of fiscal illusion. Public Choice 122(1), 39-68.

Schneider, F., A. Buehn, and C. E. Montenegro (2010). New estimates for the shadow economies all over the world. International Economic Journal 24 (4), 443-461.

Slemrod, J. (1995). Income creation or income shifting? behavioral responses to the tax reform act of 1986. The American Economic Review 85(2), pp. 175-180.

Slemrod, J. (2007). Cheating ourselves: The economics of tax evasion. Journal of Economic Perspectives 21(1), 25-48.

Slemrod, J. (2008). Does it matter who writes the check to the government? the economics of tax remittance. National Tax Journal 61, 251-75.

Slemrod, J. and C. Weber (2012). Evidence of the invisible: toward a credibility revolution in the empirical analysis of tax evasion and the informal economy. International Tax and Public Finance 19, 25-53.

Slonim, R. and A. E. Roth (1998). Learning in high stakes ultimatum games: An experiment in the slovak republic. Econometrica $66(3)$.

Smith, V. L. (1962). An experimental study of competitive market behavior. Journal of Political Economy 70, 322.

Torgler, B. (2002). Speaking to theorists and searching for facts: Tax morale and tax compliance in experiments. Journal of Economic Surveys 16(5), 657-683.

Torgler, B. (2007). Tax Compliance and Tax Morale: A Theoretical and Empirical Analysis. Cheltenham, UK: Edward Elgar.

Tran, A. and N. Nguyen (2014). The darker side of private ownership: Tax manipulation in vietnamese privatized firms. Indiana university working paper.

Wilcoxon, F. (1945). Individual comparisons by ranking methods. Biometrics 1, 80-83.

Yaniv, G. (1995). A note on the tax-evading firm. National Tax Journal 48(1), 113-120. 


\section{Tables and Figures}

\section{Tables}

Table 1: Demand and Supply Schedules

\begin{tabular}{lcccccc}
\hline \multicolumn{3}{c}{ Buyer } & & & \multicolumn{3}{c}{ Seller } \\
\cline { 1 - 2 } \cline { 6 - 7 } Subject & Value 1 & Value 2 & & Subject & Cost 1 & Cost 2 \\
\hline 1 & 82 & 52 & & 1 & 18 & 48 \\
2 & 77 & 72 & & 2 & 23 & 28 \\
3 & 67 & 37 & & 3 & 33 & 63 \\
4 & 62 & 42 & & 4 & 38 & 58 \\
5 & 57 & 47 & & 5 & 43 & 53 \\
\hline
\end{tabular}

Notes: Reported are demand and supply schedules.

Table 2: Summary statistics of Demographic Variables

\begin{tabular}{lccccc}
\hline & Gender & Age & German & Tax Morale & Econ \\
\hline \multicolumn{5}{c}{ Control } & Group (Non-Evaders) \\
\hline Mean & 0.43 & 24.90 & 0.72 & 0.25 & 0.43 \\
St. Dev. & 0.50 & 6.87 & 0.46 & 0.44 & 0.50 \\
N. of Subjects & 40 & 40 & 39 & 40 & 40 \\
\hline & \multicolumn{5}{c}{ Treatment Group (Evaders) } \\
\hline Mean & 0.60 & 26.93 & 0.83 & 0.23 & 0.53 \\
St. Dev. & 0.50 & 12.25 & 0.38 & 0.42 & 0.51 \\
N. of Subjects & 40 & 40 & 40 & 40 & 40 \\
\hline P-value & 0.12 & 0.23 & 0.26 & 0.79 & 0.37 \\
\hline
\end{tabular}

Notes: Reported are the mean characteristics of treatment and control groups. Gender is a dummy that is equal to 1 if male, German is a dummy that is equal to 1 if native language is German, tax morale is a dummy that is equal to 1 for subjects who believe cheating on taxes can never be justified and Econ is a dummy that is equal to 1 if field of study is economics. One subject in the control group did not report his/her language. P-value is for the Wilcoxon rank-sum test; null hypothesis is that there is no difference in the characteristics between the two groups. 
Table 3: Summary Statistics of Choice Variables

\begin{tabular}{lccccccc}
\hline & \multicolumn{5}{c}{ Price } & & \multicolumn{2}{c}{ Units sold } & N. \\
\cline { 2 - 4 } Group & Mean & Median & Std. Dev. & & Mean & Std. Dev. & Obs. \\
\hline Non-evader & 54.98 & 54.00 & 4.99 & 6.04 & 0.53 & 647 \\
Evader & 51.24 & 51.00 & 2.50 & 6.56 & 0.51 & 704 \\
\hline & & \multicolumn{5}{c}{ Panel A: Full Sample } \\
\hline Non-evader & 54.35 & 54.00 & 3.92 & 5.96 & 0.47 & 308 \\
Evader & 51.63 & 51.00 & 1.69 & 6.50 & 0.50 & 336 \\
\hline P-value & 0.00 & 0.00 & - & 0.00 & - & - \\
\hline
\end{tabular}

Notes: Reported is the mean and median market price and mean number of units sold in each group. Price is the price at which each unit in a given market period is sold. Units sold is the number of units sold in a market period. Panel A uses all completed contracts from periods 1 to 27 and panel $\mathrm{B}$ uses all completed contracts in periods 15 to 27 . P-value is for the Wilcoxon rank-sum test; null hypothesis is that there is no difference between the two groups.

Table 4: Impact of treatment on mean market price

\begin{tabular}{|c|c|c|c|c|}
\hline & Model 1 & Model 2 & Model 3 & Model 4 \\
\hline & \multicolumn{4}{|c|}{ Panel A: Full Sample } \\
\hline Treat & $\begin{array}{c}-3.750 * * * \\
(1.009)\end{array}$ & $\begin{array}{c}-3.750^{* * *} \\
(1.077)\end{array}$ & $\begin{array}{c}-4.300^{* * *} \\
(0.347)\end{array}$ & $\begin{array}{c}-4.300 * * * \\
(0.371)\end{array}$ \\
\hline Constant & $\begin{array}{c}55.008^{* * *} \\
(0.727)\end{array}$ & $\begin{array}{c}54.181^{* * *} \\
(1.247)\end{array}$ & $\begin{array}{c}48.868^{* * *} \\
(2.632)\end{array}$ & $\begin{array}{c}48.040 * * * \\
(3.407)\end{array}$ \\
\hline $\mathrm{R} 2$ & 0.499 & 0.517 & 0.737 & 0.754 \\
\hline \multirow[t]{2}{*}{$\mathrm{N}$} & 216 & 216 & 216 & 216 \\
\hline & \multicolumn{4}{|c|}{ Panel B: Period>14 } \\
\hline Treat & $\begin{array}{c}-2.701^{* * *} \\
(0.795)\end{array}$ & $\begin{array}{c}-2.701^{* * *} \\
(0.847)\end{array}$ & $\begin{array}{c}-2.651^{* * *} \\
(0.075)\end{array}$ & $\begin{array}{c}-2.651^{* * *} \\
(0.081)\end{array}$ \\
\hline Constant & $\begin{array}{c}54.362^{* * *} \\
(0.539)\end{array}$ & $\begin{array}{c}54.297^{* * *} \\
(0.516)\end{array}$ & $\begin{array}{c}49.508^{* * *} \\
(0.572)\end{array}$ & $\begin{array}{c}49.443^{* * *} \\
(0.750)\end{array}$ \\
\hline $\mathrm{R} 2$ & 0.553 & 0.563 & 0.884 & 0.894 \\
\hline $\mathrm{N}$ & 104 & 104 & 104 & 104 \\
\hline Control variables & No & No & Yes & Yes \\
\hline Period FE & No & Yes & No & Yes \\
\hline
\end{tabular}

Notes: Robust standard errors adjusted for clustering at the session level are in parentheses; $*$ significant at $10 \%$; $* *$ significant at $5 \%$; *** significant at $1 \%$. Estimates are based on equation (14) with the dependent variable defined as mean market price in a given market period. Panel A uses all completed contracts from periods 1 to 27 , panel B uses all completed contracts in periods 15 to 27 . Period FE is period fixed effects. 
Table 5: Impact of treatment on median and ask market price

\begin{tabular}{|c|c|c|c|c|}
\hline & Model 1 & Model 2 & Model 3 & Model 4 \\
\hline & \multicolumn{4}{|c|}{ Panel A: Median Ask Price $\left(P_{50}\right)$} \\
\hline Treat & $\begin{array}{c}-2.087^{* * *} \\
(0.625)\end{array}$ & $\begin{array}{c}-2.087^{* * *} \\
(0.665)\end{array}$ & $\begin{array}{c}-1.589^{* * *} \\
(0.218)\end{array}$ & $\begin{array}{c}-1.589 * * * \\
(0.233)\end{array}$ \\
\hline Constant & $\begin{array}{c}53.779^{* * *} \\
(0.089)\end{array}$ & $\begin{array}{c}53.918^{* * *} \\
(0.222)\end{array}$ & $\begin{array}{c}60.175^{* * *} \\
(1.655)\end{array}$ & $\begin{array}{c}60.314^{* * *} \\
(1.809)\end{array}$ \\
\hline $\mathrm{R} 2$ & 0.538 & 0.563 & 0.853 & 0.878 \\
\hline \multirow[t]{2}{*}{$\mathrm{N}$} & 104 & 104 & 104 & 104 \\
\hline & \multicolumn{4}{|c|}{ Panel B: Ask Price (P) } \\
\hline Treat & $\begin{array}{c}-2.720^{* * *} \\
(0.798)\end{array}$ & $\begin{array}{c}-2.721^{* * *} \\
(0.808)\end{array}$ & $\begin{array}{c}-2.662^{* * *} \\
(0.065)\end{array}$ & $\begin{array}{c}-2.660^{* * *} \\
(0.069)\end{array}$ \\
\hline Constant & $\begin{array}{c}54.354^{* * *} \\
(0.543)\end{array}$ & $\begin{array}{c}54.255^{* * *} \\
(0.486)\end{array}$ & $\begin{array}{c}49.500^{* * *} \\
(0.491)\end{array}$ & $\begin{array}{c}49.481^{* * *} \\
(0.593)\end{array}$ \\
\hline $\mathrm{R} 2$ & 0.173 & 0.176 & 0.276 & 0.279 \\
\hline $\mathrm{N}$ & 644 & 644 & 644 & 644 \\
\hline Control variables & No & No & Yes & Yes \\
\hline Period FE & No & Yes & No & Yes \\
\hline
\end{tabular}

Notes: Robust standard errors adjusted for clustering at the session level are in parentheses; * significant at $10 \%$; ** significant at $5 \%$; *** significant at $1 \%$. Estimates are based on equation (14) with the dependent variable defined as median market price in a given market period in panel $\mathrm{A}$; and the market price for each good in each market period in Panel B. All panels use completed contracts from periods 15 to 27. Period FE is period fixed effects. 
Table 6: Impact of treatment on units sold

\begin{tabular}{|c|c|c|c|c|}
\hline & Model 1 & Model 2 & Model 3 & Model 4 \\
\hline & \multicolumn{4}{|c|}{ Panel A: Full Sample } \\
\hline Treat & $\begin{array}{c}0.336^{* * *} \\
(0.064)\end{array}$ & $\begin{array}{c}0.334^{* * *} \\
(0.068)\end{array}$ & $\begin{array}{c}0.320^{* * *} \\
(0.027)\end{array}$ & $\begin{array}{c}0.324^{* * *} \\
(0.035)\end{array}$ \\
\hline Constant & $\begin{array}{c}6.088^{* * *} \\
(0.059)\end{array}$ & $\begin{array}{c}6.525^{* * *} \\
(0.144)\end{array}$ & $\begin{array}{c}6.701^{* * *} \\
(0.406)\end{array}$ & $\begin{array}{c}7.186^{* * *} \\
(0.277)\end{array}$ \\
\hline $\mathrm{R} 2$ & 0.090 & 0.292 & 0.100 & 0.301 \\
\hline \multirow[t]{2}{*}{$\mathrm{N}$} & 1,006 & 1,006 & 1,006 & 1,006 \\
\hline & \multicolumn{4}{|c|}{ Panel B: Period $>14$} \\
\hline Treat & $\begin{array}{c}0.402^{* * *} \\
(0.125)\end{array}$ & $\begin{array}{c}0.403^{* * *} \\
(0.125)\end{array}$ & $\begin{array}{c}0.598 * * * \\
(0.051)\end{array}$ & $\begin{array}{c}0.594^{* * *} \\
(0.056)\end{array}$ \\
\hline Constant & $\begin{array}{c}5.939^{* * *} \\
(0.118)\end{array}$ & $\begin{array}{c}6.177^{* * *} \\
(0.323)\end{array}$ & $\begin{array}{c}7.891^{* * *} \\
(0.756)\end{array}$ & $\begin{array}{c}8.102^{* * *} \\
(0.878)\end{array}$ \\
\hline $\mathrm{R} 2$ & 0.148 & 0.262 & 0.191 & 0.303 \\
\hline $\mathrm{N}$ & 476 & 476 & 476 & 476 \\
\hline Control variables & No & No & Yes & Yes \\
\hline Period FE & No & Yes & No & Yes \\
\hline
\end{tabular}

Notes: Robust standard errors adjusted for clustering at the session level are in parentheses; * significant at $10 \%$; ** significant at $5 \% ;{ }^{* * *}$ significant at $1 \%$. Estimates are based on equation (14) with the dependent variable defined as the number of units sold in a given market period. Panel A uses all completed contracts from periods 1 to 27 , panel B uses all completed contracts in periods 15 to 27 . "Period FE" is period fixed effects. 
Table 7: Overview of Results

\begin{tabular}{lccc}
\hline Condition & Price & Units & EB \\
\hline No Tax & 49 & 7 & $/ /$ \\
Control & 54.35 & 5.96 & 5.50 \\
Treatment & 51.63 & 6.50 & 1.32 \\
\hline Treat Effect & -2.72 & 0.54 & -4.18 \\
\hline
\end{tabular}

Notes: The results in "No Tax" row are from Grosser and Reuben (2013) who use identical supply and demand schedules in an experimental double auction without taxes. "Control" and "Treatment" refer to the groups without and with evasion opportunity, respectively. Reported are the mean prices and number of units traded. The excess burden "EB" of the per-unit tax is calculated based on the simple Harberger triangle. "Treat Effect" indicates the non-parametric treatment effect defined as the difference between treatment and control group. All numbers expressed in Experimental Currency Units.

\section{Figures}

Figure 1: Supply and Demand Schedule

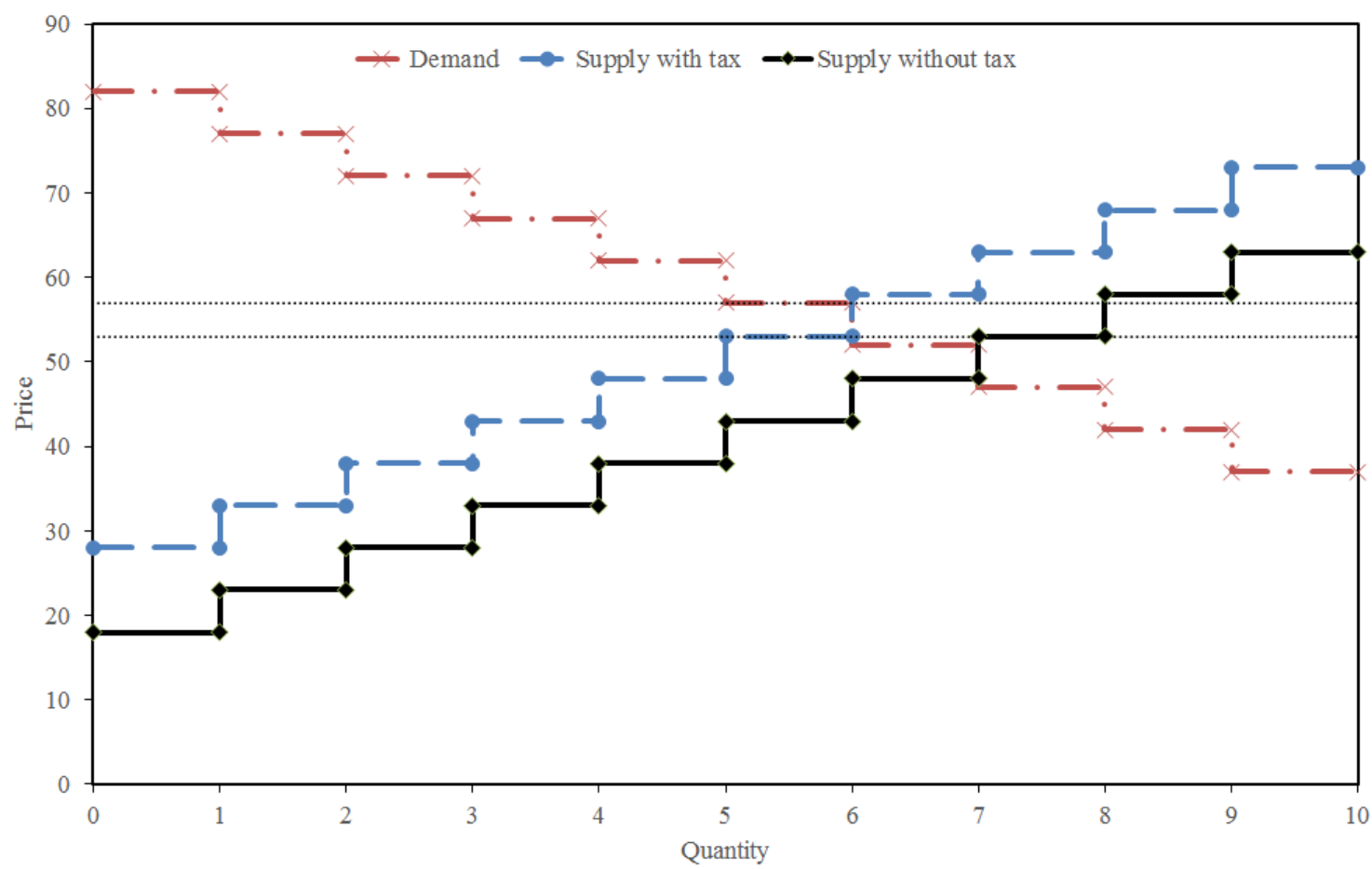

Note: The figure is adapted from Grosser and Reuben (2013, page 42, Figure 1). It shows the demand schedule for buyers and the supply schedule for sellers with and without the per unit tax. The predicted equilibrium occurs where the curves intersect: quantity $q=7$ and price $p$ between 48 and 52 without tax and quantity $q=6$ and price $p$ between 53 and 57 with the ECU 10 per unit tax. 
Figure 2: Economic incidence of tax on seller
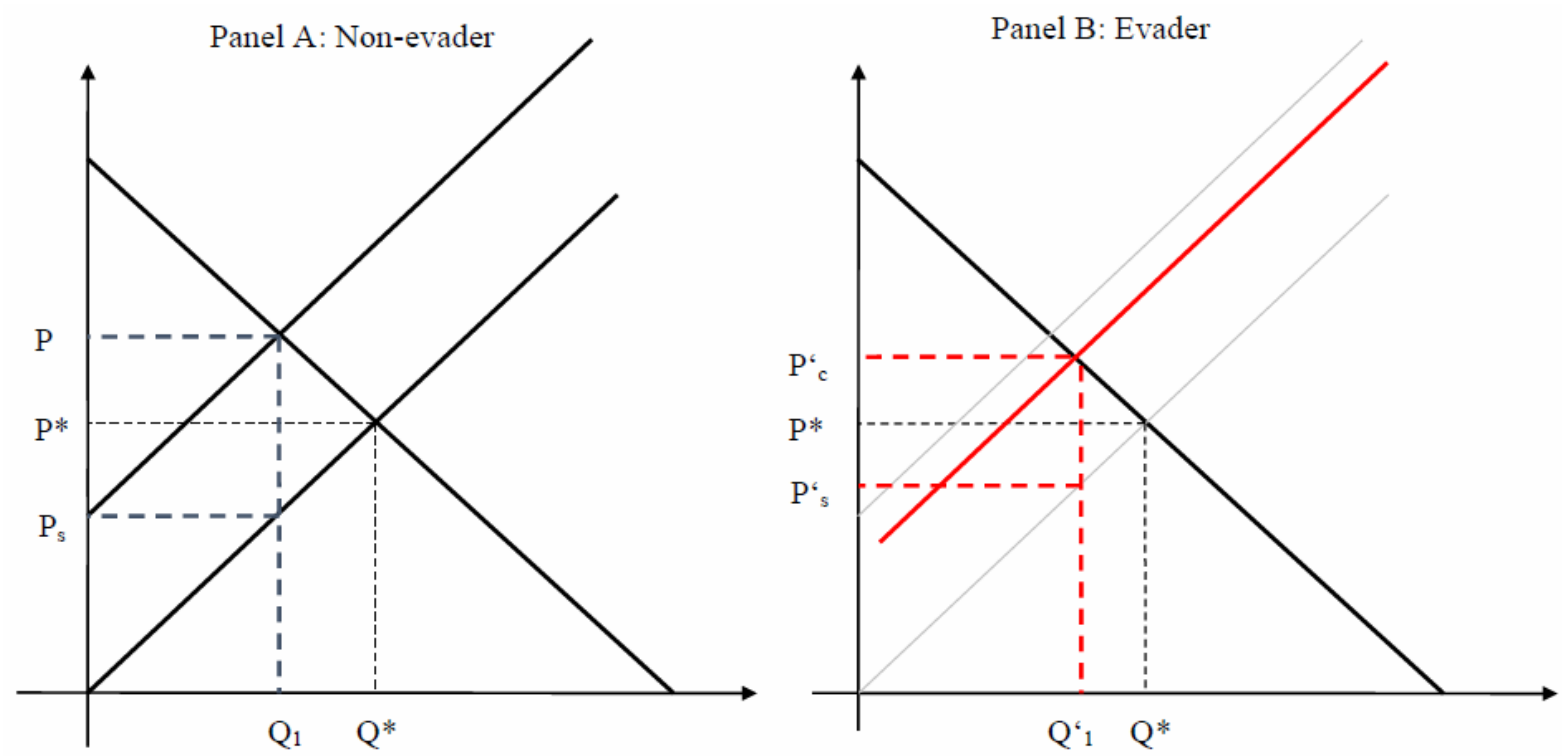

Notes: The imposition of a per-unit tax would ordinarily cause the supply curve to shift to the left and the market equilibrium to move from point $\left(P^{*}, Q^{*}\right)$ to $\left(P_{c}, Q_{1}\right)$ as illustrated in panel A. Because sellers are able to evade the tax, the supply curve shifts by a smaller amount causing the equilibrium to move from $\left(P^{*}, Q^{*}\right)$ to $\left(P_{c}^{\prime}, Q_{1}^{\prime}\right)$ as illustrated in panel B, where $P_{c}^{\prime}<P_{c}$. 
Figure 3: Average market price by period and treatment

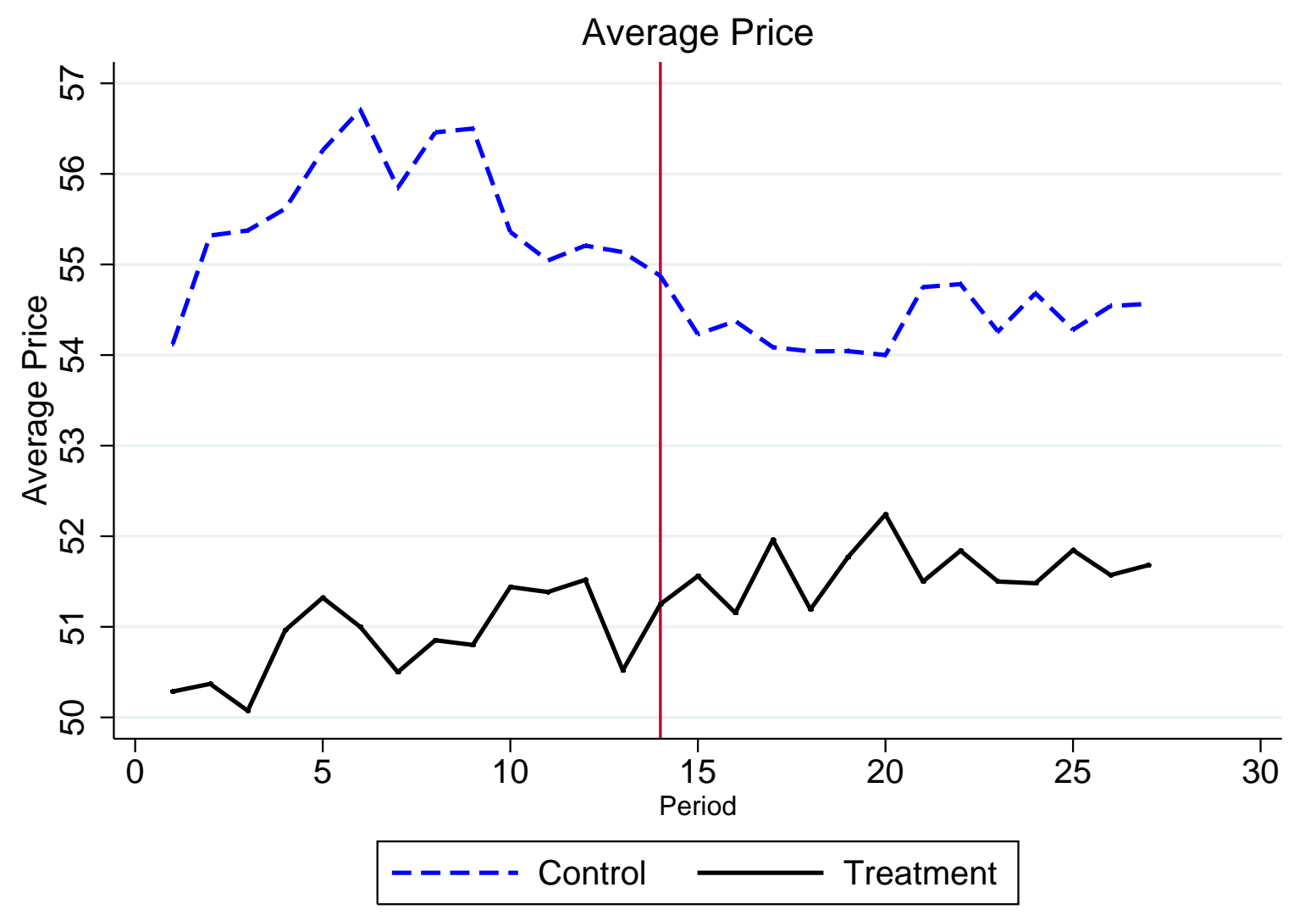

Notes: Reported is the average market price $\bar{P}$ in each period for the treatment and control groups. The vertical line indicates period 14; empirical results are based on market periods 15 to 27 . 
Figure 4: Median market price by period and treatment

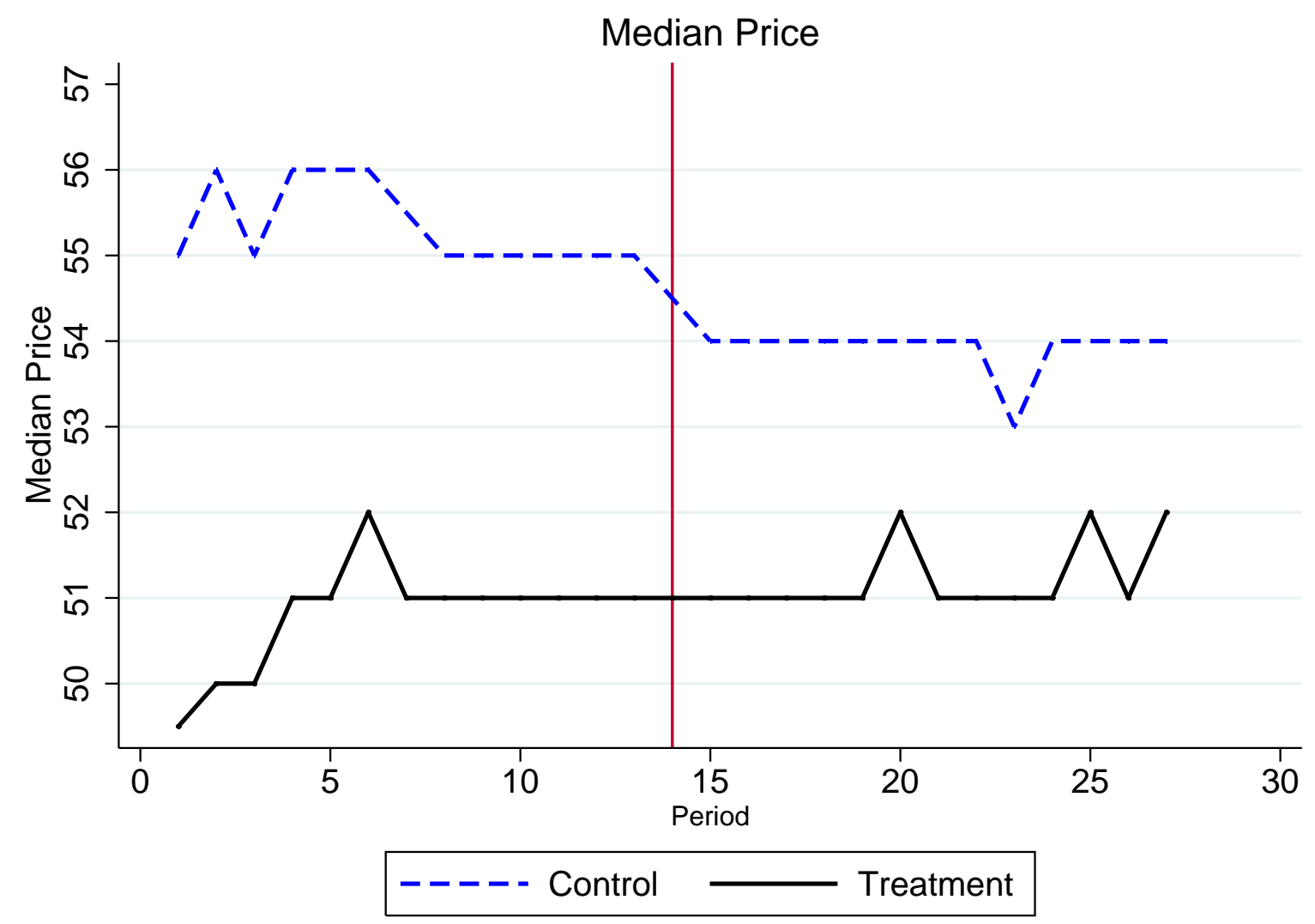

Notes: Reported is the median market price $P_{50}$ in each period for the treatment and control groups. The vertical line indicates period 14; empirical results are based on market periods 15 to 27. 
Figure 5: Units sold by period and treatment

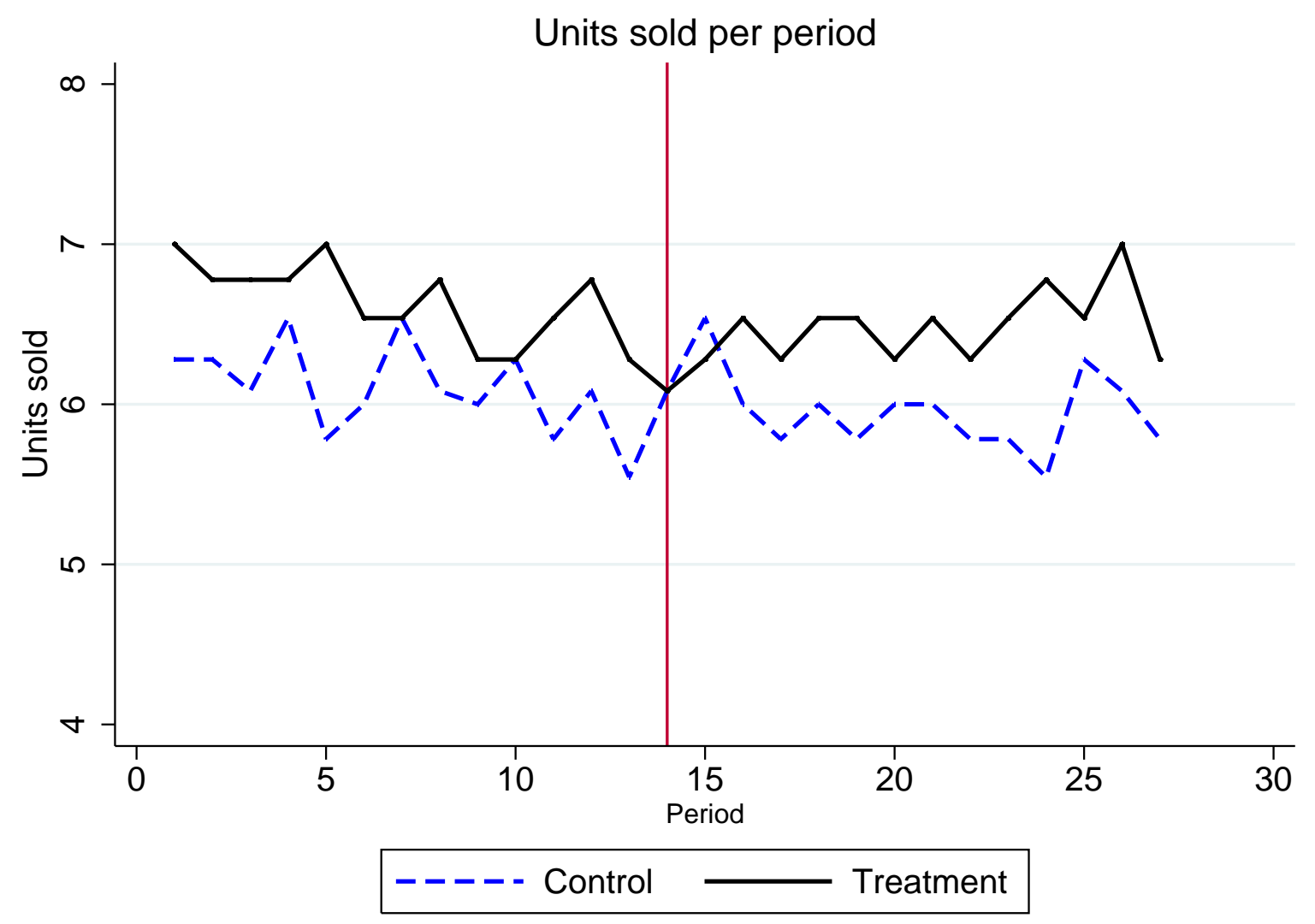

Notes: Reported is the number of units sold in each period for the treatment and control groups. The vertical line indicates period 14; empirical results are based on market periods 15 to 27 . 


\section{Appendices}

\section{A Tables}

Table 8: Impact of treatment on market price

\begin{tabular}{lcccccc}
\hline & Model 1 & Model 2 & Model 3 & Model 4 & Model 5 & Model 6 \\
\hline \multirow{2}{*}{ Treat } & \multicolumn{2}{c}{ Ask Price } & \multicolumn{2}{c}{ Mean Ask Price } & \multicolumn{2}{c}{ Median Ask Price } \\
& $-2.662^{* * *}$ & $-2.660^{* * *}$ & $-2.651^{* * *}$ & $-2.651^{* * *}$ & $-1.589^{* * *}$ & $-1.589^{* * *}$ \\
Age & $(0.065)$ & $(0.069)$ & $(0.075)$ & $(0.081)$ & $(0.218)$ & $(0.233)$ \\
& $-0.367^{* * *}$ & $-0.370^{* * *}$ & $-0.368^{* * *}$ & $-0.368^{* * *}$ & $-0.641^{* * *}$ & $-0.641^{* * *}$ \\
Gender & $(0.017)$ & $(0.017)$ & $(0.021)$ & $(0.022)$ & $(0.059)$ & $(0.064)$ \\
& $-21.352^{* * *}$ & $-21.389^{* * *}$ & $-21.435^{* * *}$ & $-21.435^{* * *}$ & $-17.990^{* * *}$ & $-17.990^{* * *}$ \\
German & $(0.177)$ & $(0.174)$ & $(0.219)$ & $(0.234)$ & $(0.633)$ & $(0.676)$ \\
Tax Morale & $29.607^{* * *}$ & $29.642^{* * *}$ & $29.663^{* * *}$ & $29.663^{* * *}$ & $22.833^{* * *}$ & $22.833^{* * *}$ \\
& $(0.347)$ & $(0.329)$ & $(0.410)$ & $(0.438)$ & $(1.186)$ & $(1.267)$ \\
Economics & $-1.274^{* * *}$ & $-1.258^{* * *}$ & $-1.245^{* * *}$ & $-1.245^{* * *}$ & -0.921 & -0.921 \\
& $(0.219)$ & $(0.222)$ & $(0.254)$ & $(0.271)$ & $(0.735)$ & $(0.786)$ \\
Constant & $5.126^{* * *}$ & $5.141^{* * *}$ & $5.156^{* * *}$ & $5.156^{* * *}$ & $2.562^{* * *}$ & $2.562^{* * *}$ \\
& $(0.153)$ & $(0.162)$ & $(0.183)$ & $(0.195)$ & $(0.529)$ & $(0.565)$ \\
R2 & $49.500^{* * *}$ & $49.481^{* * *}$ & $49.508^{* * *}$ & $49.443^{* * *}$ & $60.175^{* * *}$ & $60.314^{* * *}$ \\
N & $(0.491)$ & $(0.593)$ & $(0.572)$ & $(0.750)$ & $(1.655)$ & $(1.809)$ \\
Period FE & 0.276 & 0.279 & 0.884 & 0.894 & 0.853 & 0.878 \\
\hline \multirow{2}{*}{ F } & 644 & 644 & 104 & 104 & 104 & 104 \\
& No & Yes & No & Yes & No & Yes \\
\hline
\end{tabular}

Notes: Robust standard errors adjusted for clustering at the session level are in parentheses; * significant at $10 \%$; ** significant at 5\%; *** significant at $1 \%$. Estimates are based on equation (14) with the dependent variable defined as the market price for each good in each market period in Models 1 and 2; mean market price in a given market period in Models 3 and 4; and median market price in a given market period in Models 5 and 6 . All panels use completed contracts from periods 15 to 27. Period FE is period fixed effects. Gender is a dummy that is equal to 1 if male, German is a dummy that is equal to 1 if native language is German, tax morale is a dummy that is equal to 1 for subjects who believe cheating on taxes can never be justified and Field of study is a dummy that is equal to 1 if field of study is economics. 
Table 9: Impact of treatment on units sold

\begin{tabular}{lcccc}
\hline & Model 1 & Model 2 & Model 3 & Model 4 \\
\hline Treat & $0.539^{* * *}$ & $0.540^{* * *}$ & $0.385^{* * *}$ & $0.383^{* * *}$ \\
Age & $(0.171)$ & $(0.173)$ & $(0.131)$ & $(0.131)$ \\
& & & -0.017 & -0.017 \\
Gender & & $(0.035)$ & $(0.035)$ \\
& & & $2.349^{* * *}$ & $2.343^{* * *}$ \\
German & & & $(0.353)$ & $(0.363)$ \\
& & & $-2.000^{* * *}$ & $-1.973^{* * *}$ \\
Tax Morale & & & $(0.691)$ & $(0.691)$ \\
& & & 0.495 & 0.479 \\
Economics & & & $-0.456)$ & $(0.448)$ \\
& & & $(0.305)$ & -0.349 \\
Constant & $5.961^{* * *}$ & $6.147^{* * *}$ & $6.832^{* * *}$ & $7.005^{* * *}$ \\
& $(0.088)$ & $(0.231)$ & $(0.978)$ & $(1.064)$ \\
R2 & 0.235 & 0.315 & 0.352 & 0.433 \\
N & 644 & 644 & 644 & 644 \\
\hline Control variables & No & No & Yes & Yes \\
Period FE & No & Yes & No & Yes \\
\hline
\end{tabular}

Notes: Robust standard errors adjusted for clustering at the session level are in parentheses; * significant at $10 \%$; $* *$ significant at $5 \%$; *** significant at $1 \%$. Estimates are based on equation (14) with the dependent variable defined as the number of units sold in a given market period. Estimation is based on all completed contracts in periods 15 to 27 . Period $\mathrm{FE}$ is period fixed effects. Gender is a dummy that is equal to 1 if male, German is a dummy that is equal to 1 if native language is German, tax morale is a dummy that is equal to 1 for subjects who believe cheating on taxes can never be justified and Field of study is a dummy that is equal to 1 if field of study is economics. 


\section{B Figures}

Figure 6: Cumulative distribution of market price by treatment

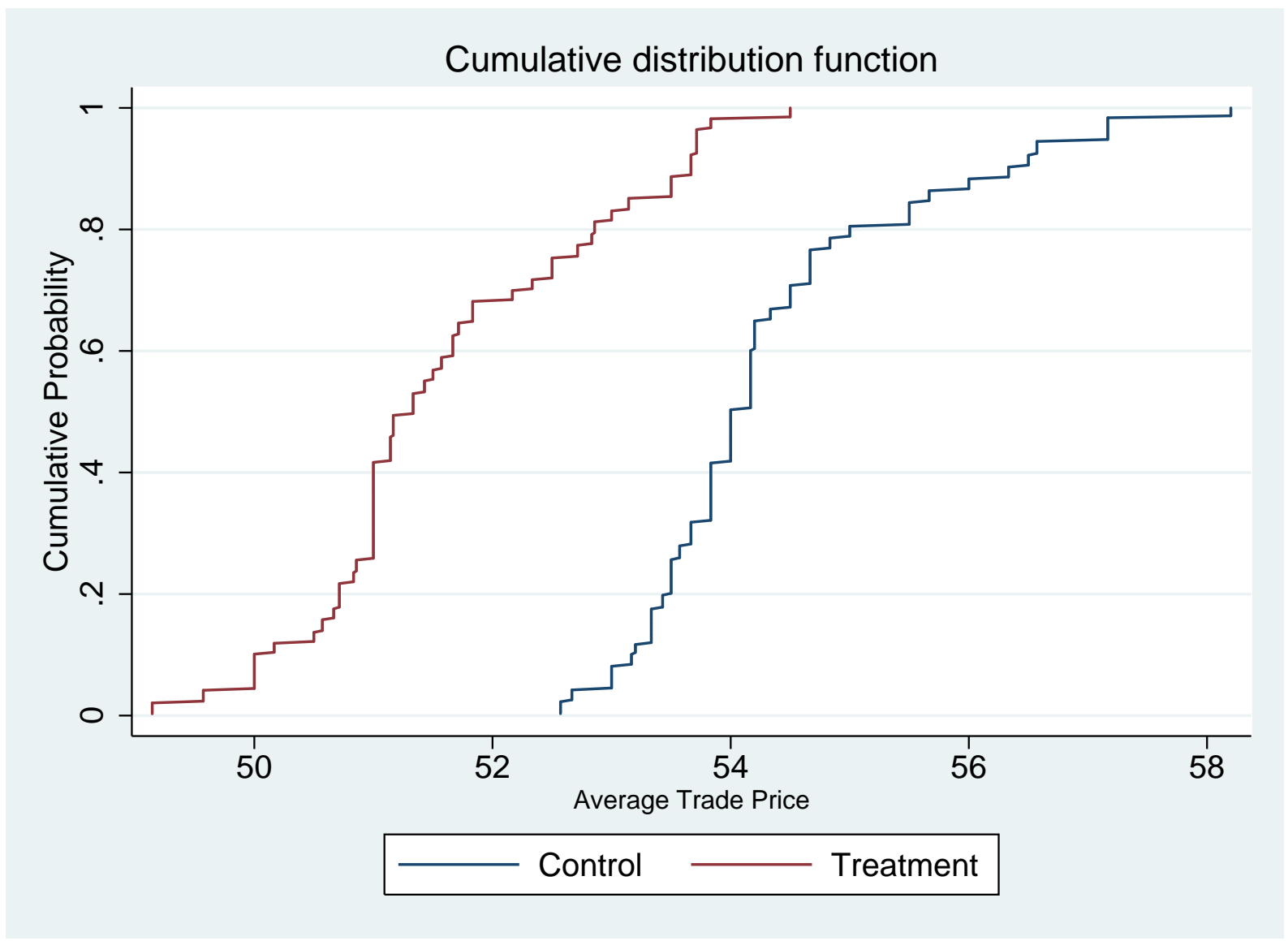

Notes: Reported is the cumulative distribution of average market price $\bar{P}$ for the treatment and control groups. Distributions are based on data from market periods 15 to 27 . Two-sample Kolmogorov-Smirnov test for equality of distribution functions reports a maximum difference in distributions of 0.770 with pvalue of 0.000 . This implies that the null hypothesis that the distributions are equal is rejected. 
Figure 7: Cumulative distribution of market price by treatment

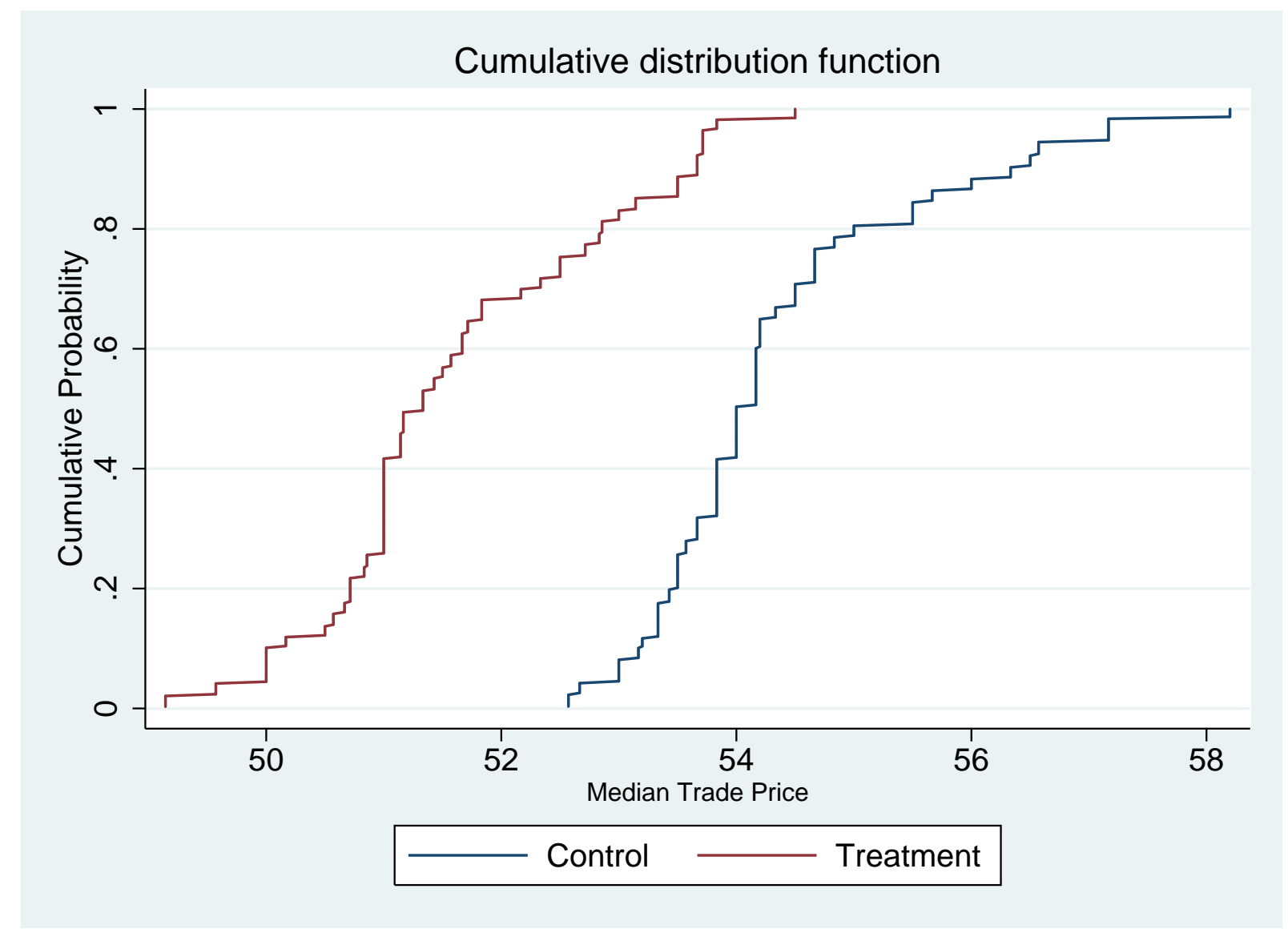

Notes: Reported is the cumulative distribution of median market price $P_{50}$ for the treatment and control groups. Distributions are based on data from market periods 15 to 27. Two-sample Kolmogorov-Smirnov test for equality of distribution functions reports a maximum difference in distributions of 0.751 with pvalue of 0.000 . This implies that the null hypothesis that the distributions are equal is rejected. 
Figure 8: Screenshot of the Market Place

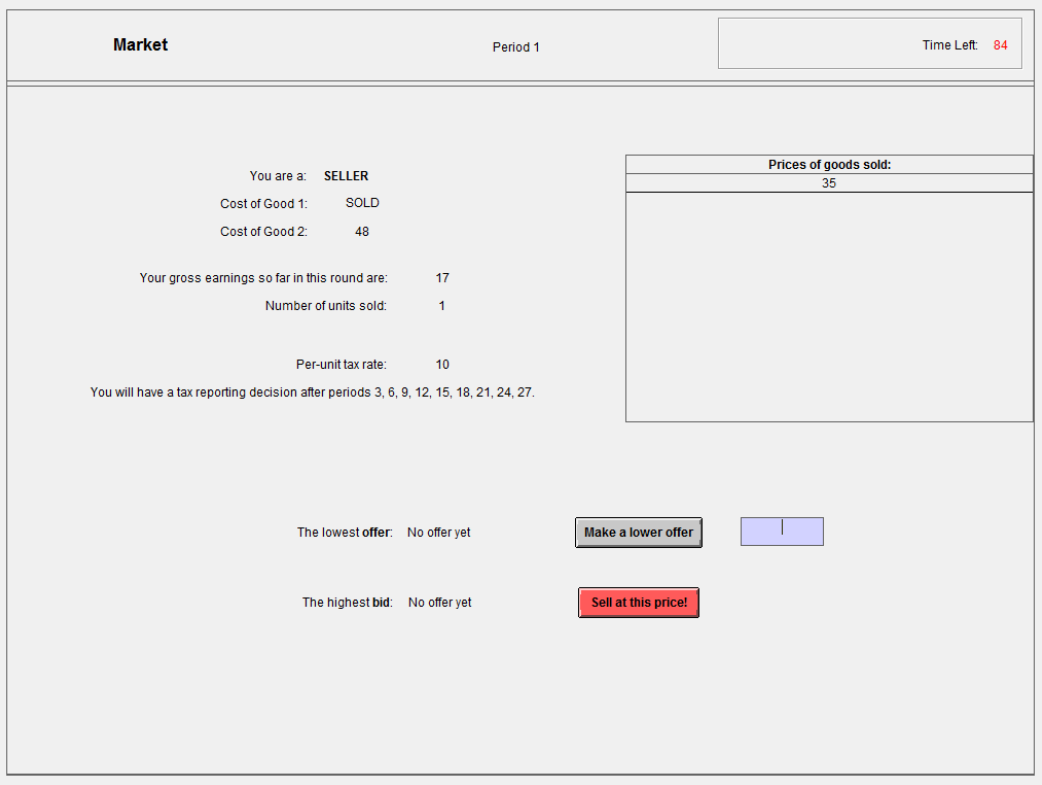

Note: Screenshot of the lab experimental double-auction market place. The screen displays the market place for a seller in the treatment group with evasion opportunity. The seller has sold her first unit at a price of 35. The cost for the first unit was 18, yielding a current gross-income of 17 . Her second unit with cost 48 is not traded at this point. The screen shown is translated to English, the original experiment was conducted in German. The market place is based on Grosser and Reuben (2013). 


\section{Instructions}

The following pages contain the translated instructions for both treatment groups. The original German versions are available from the authors upon request.

\section{C.1 No-Evasion opportunity control group}

Welcome and thank you for participating in our experiment. From now on until the end of the experiment, please refrain from communicating with other participants. If you do not abide by this rule, we will have to exclude you from the experiment.

We kindly ask you to read the instructions thoroughly. If you have any questions after reading the instructions or during the experiment, please raise your hand and one of the instructors will come to you and answer your question in person. Your payment and your decisions throughout the experiment will be treated confidentially.

You can earn money in this experiment. How much you earn depends on your decisions and the decisions of other participants. During the experiment, your payments will be calculated in a virtual currency: Experimental Currency Units (ECU). 30 ECU correspond to 1 Euro. After the experiment, your pay-off will be converted to Euro and given to you in cash. Additionally, you will receive a show-up fee of 2.50 Euro.

\section{The Experiment}

\section{$\underline{\text { Roles }}$}

At the beginning of the experiment, the computer will randomly assign five participants to the role of "sellers" and five other participants to the role of "buyers". Therefore, you will either be a buyer or a seller. Your role as seller or buyer will remain the same throughout the experiment. You will only know your own role and not the roles of other participants.

\section{Overview}

The experiment consists of 3 practice rounds and 27 paying rounds. At the beginning of each round, all buyers and sellers trade a fictitious good in a market place. As a buyer, you can buy units of the fictitious good and as a seller you can sell units. You can earn ECU in the market place and your earnings depend on your decisions and the decisions of the other participants. Each unit sold will be subject to a per unit tax of 10 ECU for sellers. The tax rate is the same for all sellers and is due at the end of every third round. Details on the market place will be explained further below. All tax revenues paid by you and all other participants will be donated to the German Red Cross. 


\section{The Market Place}

\section{Basics}

The market place is opened for two minutes at the beginning of each round. All buyers and sellers trade a fictitious good. In each market period, each seller can sell two units of the fictitious good and each buyer can buy two units of the good.

\section{Units, costs, and values}

If you are a seller, you will be given the costs for two units of a fictitious good at the beginning of the experiment. These units shall be denoted "Unit 1" and "Unit 2", where Unit 1 costs less than Unit 2. The cost of these units to you is the same in all rounds. However, the cost of each seller's units will differ from the cost of other sellers' units. Each seller only knows her own costs.

If you are a buyer, you will be given the values for two units of a fictitious good at the beginning of the experiment. These units shall be denoted "Unit 1" and "Unit 2" where Unit 1 values more than Unit 2. The value of these units to you is the same in all rounds. However, the value of each buyer's units will differ from the value of other buyers' units. Each buyer only knows her own values.

\section{Asks, Bids, and Transactions}

Sellers can make "asks" and Buyers can make "bids" during the trading period. All asks and bids are visible to everyone through the screen that appears during the two minutes of trading. This screen will also state your type (Seller or Buyer), the time left in the trading period and the costs or values that you were assigned for each Unit. Each Seller can first sell Unit 1 and afterward Unit 2. Accordingly, Buyers can first buy Unit 1 and then Unit 2.

Sellers cannot sell goods at prices lower than the assigned cost for the respective Unit. Buyers cannot buy at prices that exceed their assigned value for the respective Unit.

Sellers can make asks at any time during the trading period but each ask has to be lower than the current lowest ask on the market. Similarly, Buyers can always propose bids as long as they are larger than the current largest bid on the market.

To realize a transaction, Sellers can either accept a bid or buyers can accept an ask. The transaction price for the unit will then be equal to the accepted ask or bid.

\section{(Gross) Earnings in the Market Place}

Units that are not traded do not yield any earnings. Gross earnings for each Unit are as 
follows:

\section{For Sellers:}

Gross Earnings from selling Unit $1=$ transaction price of Unit 1 - cost of Unit 1

Gross Earnings from selling Unit $2=$ transaction price of Unit 2 - cost of Unit 2

\section{For Buyers:}

Gross Earnings from buying Unit $1=$ value of Unit 1 - transaction price of Unit 1

Gross Earnings from buying Unit $2=$ value of Unit 2 - transaction price of Unit 2

\section{Screenshots from trading market}

\section{Sellers:}

\section{Here Screenshot Sellers}

Sellers can accept a current bid by pressing "Sell at this Price". To make a new ask, Sellers have to enter their ask price into the field to the right of the "Make a smaller ask" button and press the button to submit the ask.

\section{Buyers:}

\section{Here Screenshot Buyers}

Buyers can accept the current ask by pressing "Buy at this Price". To make a new bid, Buyers have to enter their bid into the field to the right of the "Make a smaller bid" and press the button to submit the bid.

\section{Calculation of Net Income for Sellers}

After three consecutive trading periods, the screen shows how many units of the fictitious unit you have traded over the previous three rounds and the resulting gross income from the previous three periods. For each unit traded in the three previous periods, a per-unit tax of 10 ECU is due for sellers

Therefore, a seller's payment - the net income - , consists of her sum of all gross earnings from the three previous rounds, (henceforth denoted "sum gross income") minus the tax payment. The tax payment is the number of units sold over the previous three periods multiplied by the tax rate of 10 ECU. Hence: 
$\underline{\text { Net Income }}=$ sum gross income - (number of units sold in previous 3 rounds $*$ per-unit tax rate)

After every third round, sellers are informed about the net income that they earned over the previous three periods.

\section{Payment}

The first 3 rounds serve as practice rounds, in which you cannot earn money. The subsequent 27 rounds are paying rounds.

Buyers do not pay taxes so that gross earnings equal net earnings. A buyer's payoff hence equals the sum of gross earnings from all 27 trading periods.

Sellers receive a payoff that consists of the sum of all net incomes, each of which is earned after every third paying round (i.e., after paying rounds 3, 6, 9, 12, 15, 18, 21, 24, 27.)

You will be paid the payoff in cash at the end of the experiment. Additionally, each participant receives a show-up fee of 2.50 Euro. If the sum of all gross or net incomes is negative or zero, you will be paid the show-up fee; that is, you cannot make losses and will earn a minimum amount of 2.50 Euro.

\section{Final Remarks}

After the completion of all 30 rounds - 3 practice round plus 27 paying rounds - the experiment is finished. You will be asked to complete a short questionnaire at the end of the experiment while we prepare the payments. All information collected through this questionnaire, just like all data gathered during the experiment, are anonymous and exclusively used for scientific purposes. After you have completed the questionnaire, please remain seated at your booth until we call you to come up front to pick up your payment.

\section{C.2 Evasion opportunity treatment group}

Welcome and thank you for participating in our experiment. From now on until the end of the experiment, please refrain from communicating with other participants. If you do not abide by this rule, we will have to exclude you from the experiment.

We kindly ask you to read the instructions thoroughly. If you have any questions after reading the instructions or during the experiment, please raise your hand and one of the instructors will come to you and answer your question in person. Your payment and your decisions throughout the experiment will be treated confidentially. 
You can earn money in this experiment. How much you earn depends on your decisions and the decisions of other participants. During the experiment, your payments will be calculated in a virtual currency: Experimental Currency Units (ECU). 30 ECU correspond to 1 Euro. After the experiment, your pay-off will be converted to Euro and given to you in cash. Additionally, you will receive a show-up fee of 2.50 Euro.

\section{The Experiment}

\section{$\underline{\text { Roles }}$}

At the beginning of the experiment, the computer will randomly assign five participants to the role of "sellers" and five other participants to the role of "buyers". Therefore, you will either be a buyer or a seller. Your role as seller or buyer will remain the same throughout the experiment. You will only know your own role and not the roles of other participants.

\section{Overview}

The experiment consists of 3 practice rounds and 27 paying rounds. At the beginning of each round, all buyers and sellers trade a fictitious good in a market place. As a buyer, you can buy units of the fictitious good and as a seller you can sell units. You can earn ECU in the market place and your earnings depend on your decisions and the decisions of the other participants. Each unit sold will be subject to a per unit tax of 10 ECU for sellers. The tax rate is the same for all sellers and is due at the end of every third round. At the end of every third round, sellers are asked to report the number of units that they sold in the previous three market rounds. There is a $10 \%$ chance that the reported decision will be checked for accuracy. Details on the market place will be explained further below. All tax revenues paid by you and all other participants will be donated to the German Red Cross.

\section{$\underline{\text { The Market Place }}$}

\section{Basics}

The market place is opened for two minutes at the beginning of each round. All buyers and sellers trade a fictitious good. In each market period, each seller can sell two units of the fictitious good and each buyer can buy two units of the good.

\section{Units, costs, and values}

If you are a seller, you will be given the costs for two units of a fictitious good at the beginning of the experiment. These units shall be denoted "Unit 1" and "Unit 2", where 
Unit 1 costs less than Unit 2. The cost of these units to you is the same in all rounds. However, the cost of each seller's units will differ from the cost of other sellers' units. Each seller only knows her own costs.

If you are a buyer, you will be given the values for two units of a fictitious good at the beginning of the experiment. These units shall be denoted "Unit 1" and "Unit 2" where Unit 1 values more than Unit 2. The value of these units to you is the same in all rounds. However, the value of each buyer's units will differ from the value of other buyers' units. Each buyer only knows her own values.

\section{Asks, Bids, and Transactions}

Sellers can make "asks" and Buyers can make "bids" during the trading period. All asks and bids are visible to everyone through the screen that appears during the two minutes of trading. This screen will also state your type (Seller or Buyer), the time left in the trading period and the costs or values that you were assigned for each Unit. Each Seller can first sell Unit 1 and afterward Unit 2. Accordingly, Buyers can first buy Unit 1 and then Unit 2.

Sellers cannot sell goods at prices lower than the assigned cost for the respective Unit. Buyers cannot buy at prices that exceed their assigned value for the respective Unit.

Sellers can make asks at any time during the trading period but each ask has to be lower than the current lowest ask on the market. Similarly, Buyers can always propose bids as long as they are larger than the current largest bid on the market.

To realize a transaction, Sellers can either accept a bid or buyers can accept an ask. The transaction price for the unit will then be equal to the accepted ask or bid.

\section{(Gross) Earnings in the Market Place}

Units that are not traded do not yield any earnings. Gross earnings for each Unit are as follows:

\section{For Sellers:}

Gross Earnings from selling Unit $1=$ transaction price of Unit 1 - cost of Unit 1

Gross Earnings from selling Unit $2=$ transaction price of Unit 2 - cost of Unit 2

\section{For Buyers:}

Gross Earnings from buying Unit $1=$ value of Unit 1 - transaction price of Unit 1

Gross Earnings from buying Unit 2 = value of Unit 2 - transaction price of Unit 2 
Sellers:

\section{Here Screenshot Sellers}

Sellers can accept a current bid by pressing "Sell at this Price". To make a new ask, Sellers have to enter their ask price into the field to the right of the "Make a smaller ask" button and press the button to submit the ask.

\section{Buyers:}

\section{Here Screenshot Buyers}

Buyers can accept the current ask by pressing "Buy at this Price". To make a new bid, Buyers have to enter their bid into the field to the right of the "Make a smaller bid" and press the button to submit the bid.

\section{The Reporting Decision for Sellers}

After three consecutive trading periods, you will be shown the number of units traded over the three previous trading rounds and the respective gross earnings on those units. For each unit traded in the three previous periods, a per-unit tax of $\mathbf{1 0}$ ECU is due for sellers.

Sellers will then be asked to report the number of units sold in the previous three rounds for tax purposes. The reported amount may be between zero and the total number of units that were actually sold over the previous three rounds. After the reporting decision is submitted by pressing the "OK" button, the computer will determine if it is checked whether the reported number equals the actual number of units sold over the last three periods. The computer makes this call by randomly selecting an integer number between 1 and 10. The reporting decision will only be checked if the computer selects the number 1. Therefore, there is a random chance of $10 \%$ that the reporting decision will be checked.

\section{Calculation of Net Income for Sellers}

Sellers will be informed of the outcome of the random draw, and will be faced with one of the following two scenarios:

1. Computer selects a number between 2 and $\mathbf{1 0}(2,3,4,5,6,7,8,9$ or 10):

The reporting decision will not be checked. A seller's earnings after taxes - the net income -, in this case, consists of the sum of all her gross earnings from the three previous 
periods (henceforth denoted "sum gross income") minus the tax payment. The tax payment is the reported number of units sold multiplied by the tax rate of 10 ECU. Hence:

$\underline{\text { Net income }}=$ sum gross income $-($ reported number of units sold $*$ per unit tax rate $)$

\section{Computer selects number 1:}

The reporting decision will be checked. A seller's earnings after taxes - the net income -, in this case, consist of sum of all her gross earnings from the three previous periods (henceforth denoted "sum gross income") minus the tax payment. The tax payment is based on the number of units actually sold over the last three periods. If the number of units was not reported correctly, a seller will additionally have to pay a penalty that is equal to the amount of tax liability that was not paid. Hence:

$\underline{\text { Net income }}=$ sum gross income - (actual number of units sold $*$ per unit tax rate) (number of units not reported $*$ per unit tax rate)

\section{Payment}

The first 3 rounds serve as practice rounds, in which you cannot earn money. The subsequent 27 rounds are paying rounds.

Buyers do not pay taxes so that gross earnings equal net earnings. A buyer's payoff hence equals the sum of gross earnings from all 27 trading periods.

Sellers receive a payoff that consists of the sum of all net incomes, each of which is earned after every third paying round (i.e., after paying rounds $3,6,9,12,15,18,21,24$, 27.)

You will be paid the payoff in cash at the end of the experiment. Additionally, each participant receives a show-up fee of 2.50 Euro. If the sum of all gross or net incomes is negative or zero, you will be paid the show-up fee; that is, you cannot make losses and will earn a minimum amount of 2.50 Euro.

\section{Final Remarks}

After the completion of all 30 rounds - 3 practice round plus 27 paying rounds - the experiment is finished. You will be asked to complete a short questionnaire at the end of the experiment while we prepare the payments. All information collected through this questionnaire, just like all data gathered during the experiment, are anonymous and exclusively used for scientific purposes. After you have completed the questionnaire, please remain seated at your booth until we call you to come up front to pick up your payment. 